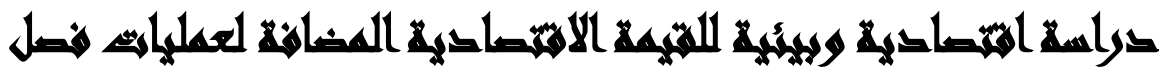

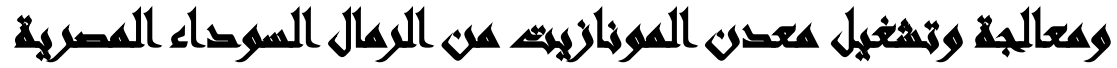

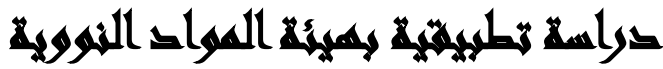

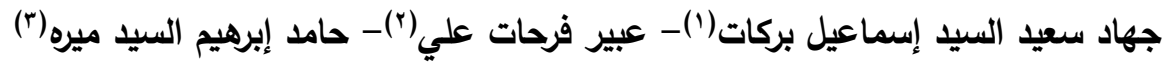

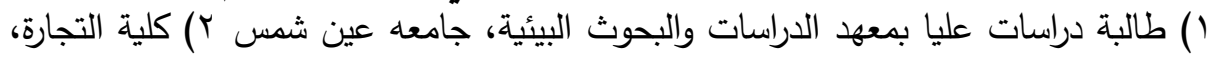
جامعة عين شمس r) هيئة المواد النووية الإسية

\section{(ll}

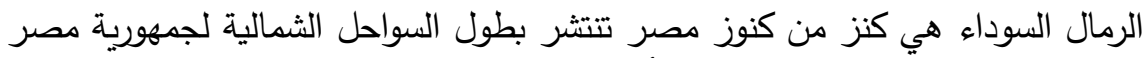

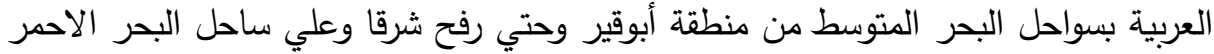

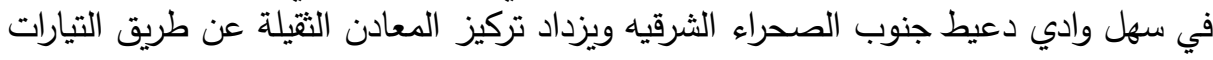

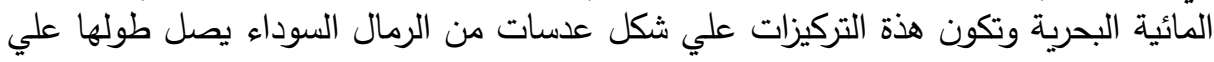

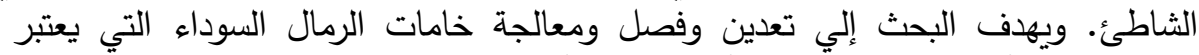

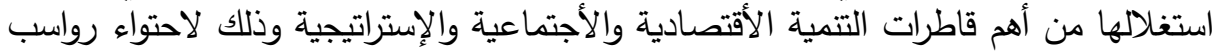

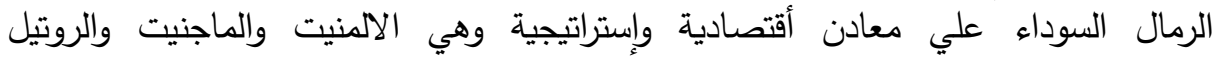

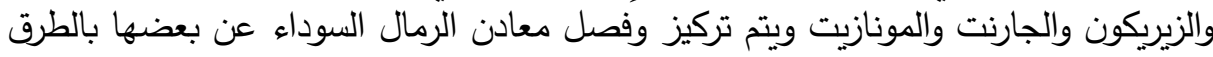

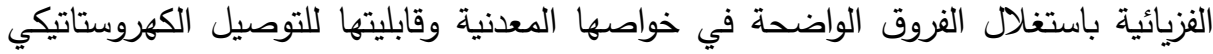

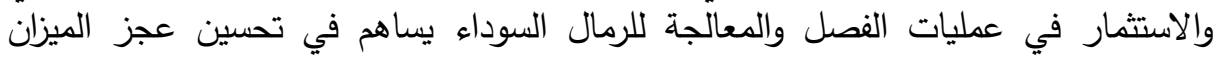

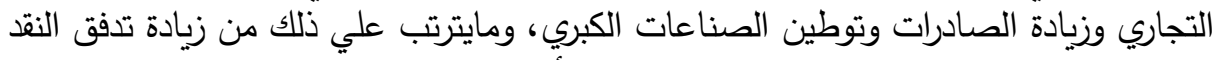

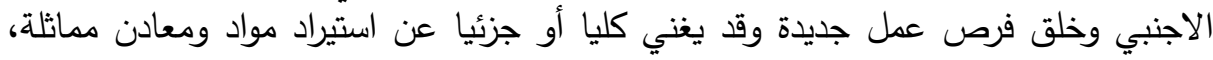

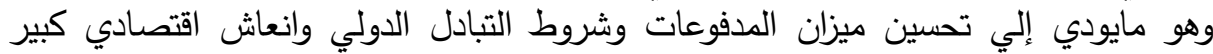

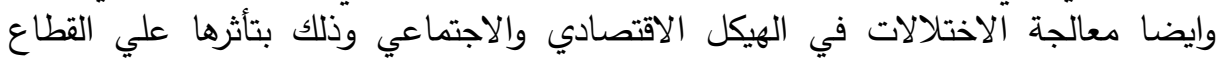

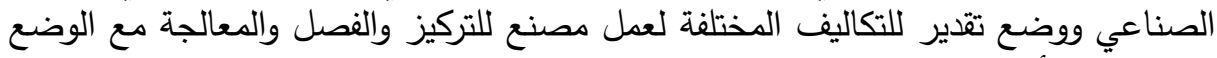
في الاعتبار أن يتوافق مع الواقع المصري من حيث مكان التتجيم الذي يتمتع باكثر احتياطي ممكن للمعادن الاقتصادية والدراسات الجيولوجية والإنية الاستكثافية وأسعار الالات.

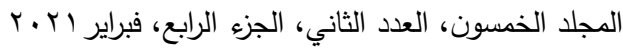

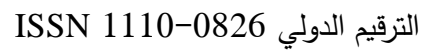


وأعتمد البحث علي المنهج الاستقرائي واشتملت منهجية جمع المعلومات علي أربعة

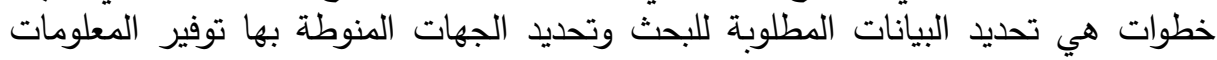

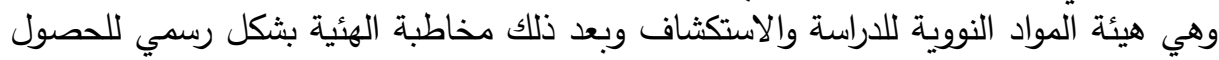
علي البيانات والاطلاع علي الاتفاقيات التي قامت بها الهيئة بهذا الصدد ثم معالجة البيانات

وجاءت نتائج البحث في أن عمليات فصل الرمال السوداء تتتج مخلفات صلبة متتوعة

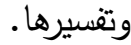

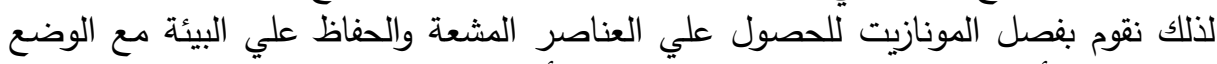

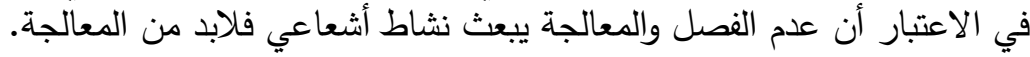

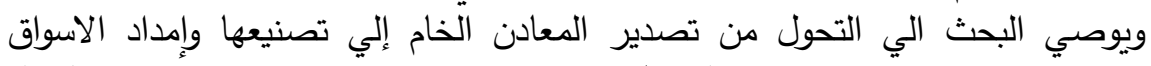

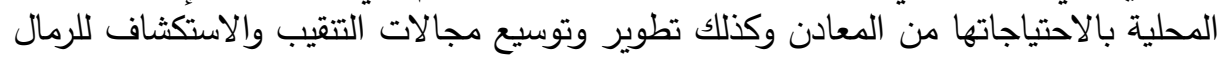

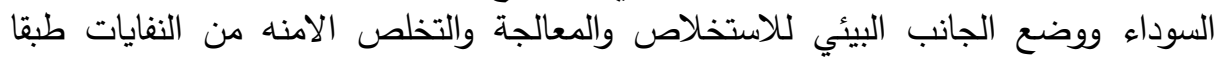
للاساليب التنظيمية التي تختارها السلطة المركزية والتي من شانها الحفاظ علي البيئة.

\section{Marall}

يشهد العالم في هذة الحقبة من الزمن ما يمكن تسميته بثورة التطور والتغيير التي يمكن

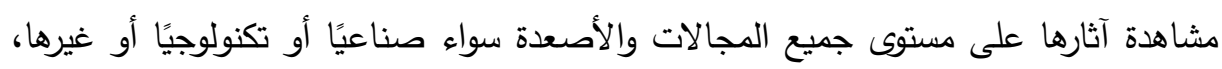
والتي توجهت بمفهوم خلق القيمة أو بمعنى آخر القيمة المضافة إلى جانب أدوات التقييم التي

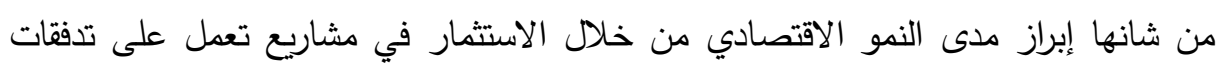
نقدية كبيرة. ويُعدُّ قطاع التعدين واستخراج وفصل المعادن من القطاعات المهمة التي تساهم في تحسين العجز في الميزان التجاري وبالتالي ميزان المدفوعات وزيادة الناتج المحلي الإجمالي،كما أن لها دورًا في تثغيل القوي العاملة، وتدخل في كثير من الصناعات التكنولوجية المهمة. وتعتبر الرمال السوداء من كنوز مصر المُهدرَة على شواطئ البحر المتوسط والبحر

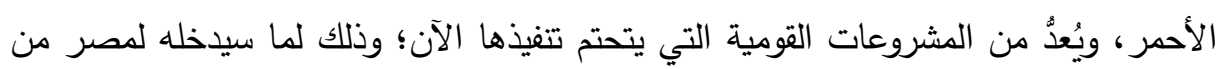

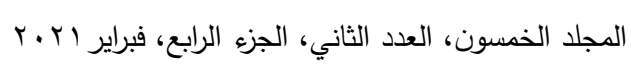

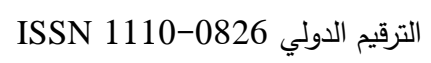


مليارات الدولارات، وهو ما يعمل على الاستغلال الأمثل للموارد الطبيعية وحماية المجتمع من الآثار البيئية والإشعاعية، وتحتوي الرمال السوداء على العديد من المعادن الثقيلة، والمعادن

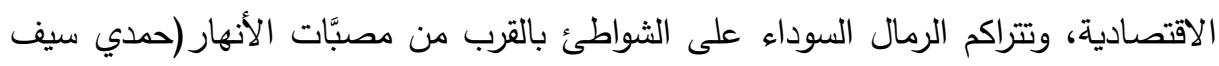

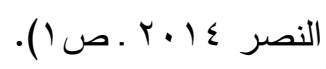

\section{And ILan}

يُعدُ قطاع التعدين من القطاعات الحيوية المهمة في مصر، ويقوم عليها العديد من

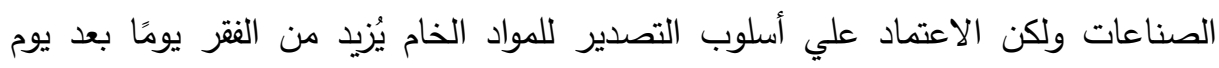

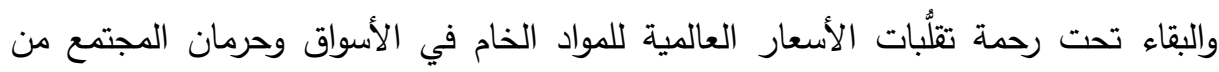

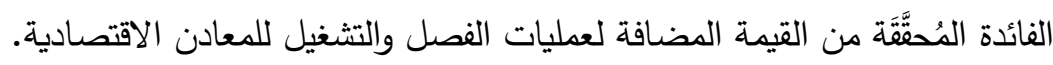
ونجد أن جمهورية مصر العربية تتوفر بها العديد من المعادن التي تم إهمالها وإهدارها

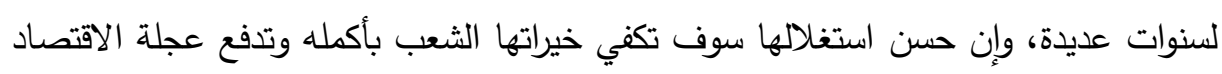

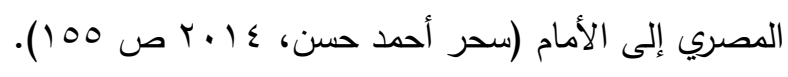
تكمن المشكلة في أهمية فصل المعادن الاقتصادية من رواسب الرمالبر الرمال السوداء ومنها معدن

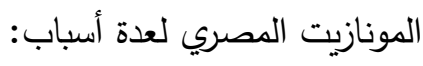

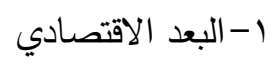
ب- البعد الاستراتيجي

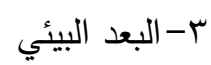
1-البعد الإقتصادي لفصل ومعالجة للمونازيت: إن تصدير المواد الخام دون فصل يؤدي إلي

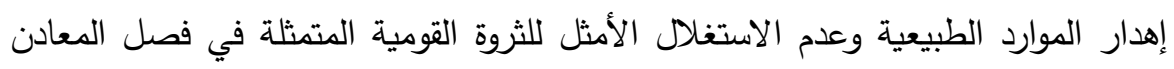

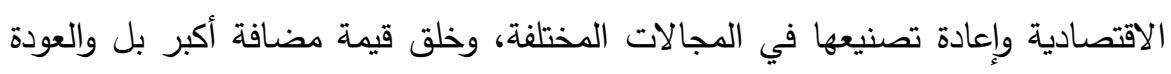
في استيراد تلك العناصر مرة أخرى ولكن بمبالغ نقدية كبيره وبالعملات الأجنبية مما يُحدِث

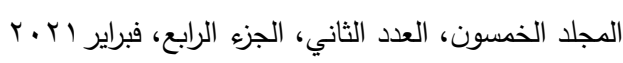

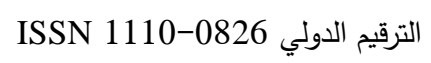


عجزًا في الميزان التجاري وحدوث الأزمات الاقتصادية، وزيادة التضخم، ورفع العملات الأجنبية، كما يؤدي الاستثمار في مجال الفصل والتشغيل إلى زيادة مستمرة في الدخل

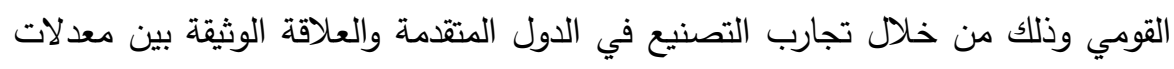

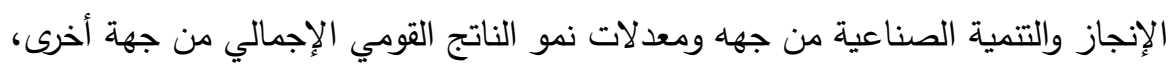

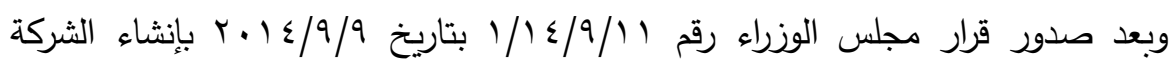
المصرية للرمال السوداء لاستغلال كثبان الرمال السوداء بساحل البحر المتوسط بمنطقة

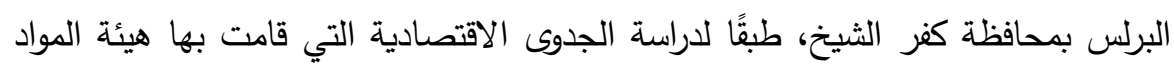

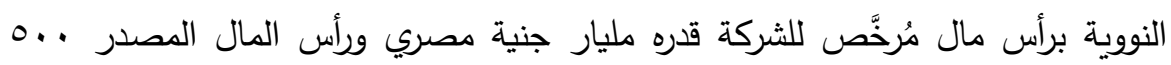

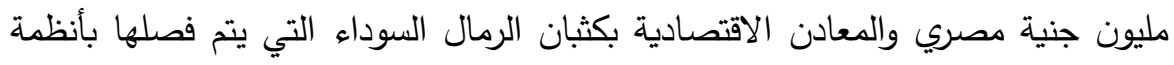

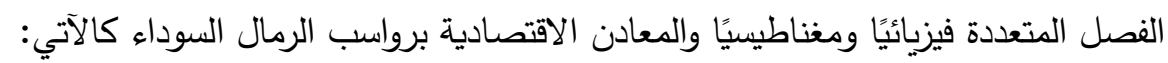

$$
\text { و }
$$

ونظرًا لما تمثله قيمة المعادن الاقتصادية من قيمة سعرية منخفضة جدًا إذا ما قورنت

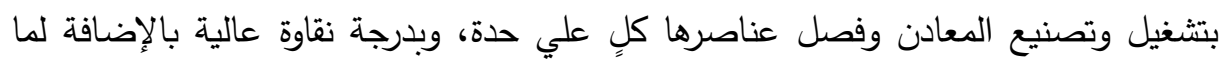
تمثلة القيمة الاقتصادية المضافة لمعدن المونازيت لما يحتوية من عناصر مُشفعَّة (اليورانيوم الثوريوم) بالإضافة لأكثر من • ؟\% عناصر أرضية نادرة مرتفعة القيمة السعرية، ومن خلال توطين التكنولوجيا الحديثة للحصول على اليورانيوم والثثريوم تقوم هيئة المواد النووية من

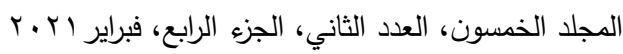

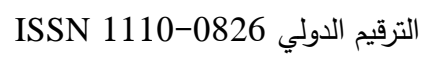




$$
\begin{aligned}
& \text { مجلة العلوم البيئية } \\
& \text { معهد الدراسات والبحوث البيئية - جامعة عين شمس لبه } \\
& \text { جهاد سعيد السيد وآخرون }
\end{aligned}
$$

الاستفادة بهما في المفاعلات النووية للأغراض السلمية بالإضافة إلى تجارب الأبحاث

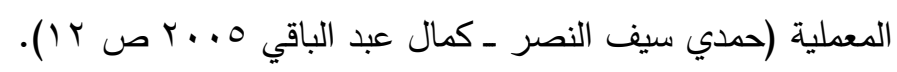

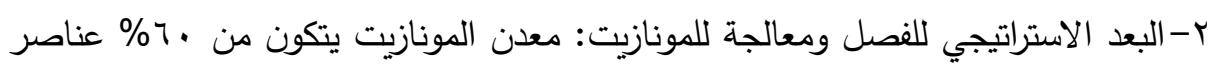

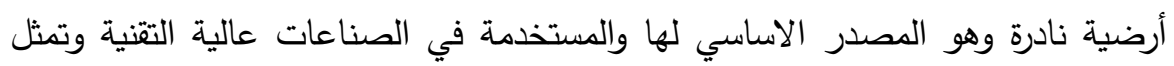
النخاع الثوكي للتصنيع التكنولوجي الحديث المعدني وغير المعدني (سعاد صالح متولي 10 النووية لأغراض سلمية، لتوليد الطاقة الكهربية على سبيل المثال ويمثل توفيرها بُعدًا

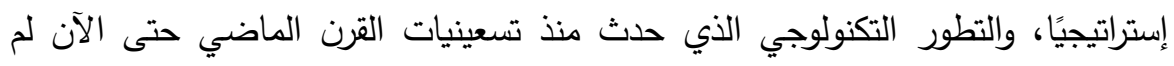
يُعطِ الوقت الكافي للدول لتصنيع خطٍٍ استراتيجية لتخزين هذة العناصر وخلق بنية تحتية

$$
\text { - ميكمن البعد الاستمة مع الأسواق العالمية. }
$$

- - صعوبة الحصول على العناصر الأرضية النادرة. وهذا ما دفع المجموعة الأوربية والأمريكية إلى تحديد لائحة بالعناصر الأرضية النادرة والتي تعتبر استراتيجية بالنسبة

r-البعد البيئي للفصل والمعالجة للمونازيت: ينتج اشعاع طبيعي بساحل الدلتا بجمهورية

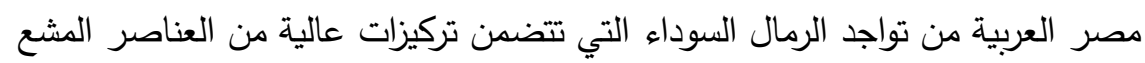

(Yassin A. Abdel Razek; Antar F. Bakhit and Ahmed F. El-Hadary, 2009 p.217)

ونظرًا لما يسببه التعرض للمعادن المشعة من تغيرات كميائية في أنسجة الكائنات الحية مما يؤدي إلى أضرار كبيرة للجسم وتزداد درجة تلك التغيرات الكميائية تبعًا لمقدار جرعة لفئه

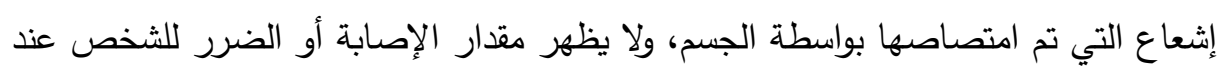

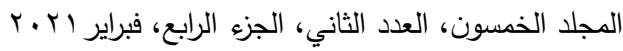

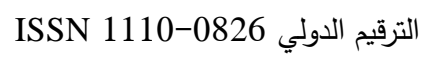


تعرضه للإشعاع إلا بعد فترة قد تتاخر الآثار المبكرة لبعض أنواع التعرض الإشعاعي إلى سنوات ويحدد نوع مصدر الإشعاع نوع الإصابة التي تتتج عنه.

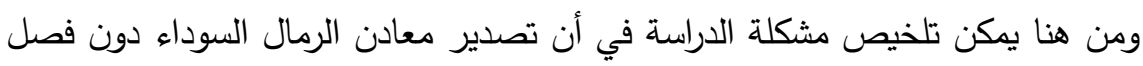

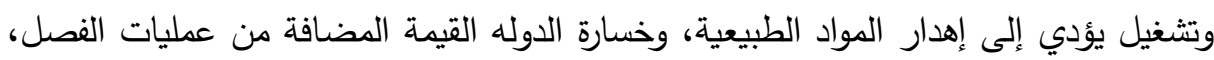
وأيضًا عدم الاستفادة من العناصر المشعة وتعرُض المواطنين في المناطق التي تتركز فيها الرمال السوداء إلى أضرار بيئية وإشعاعية مما يؤدي إلى كارثة بيئية محققة.

\section{أسهول المهنم}

• ما مدي الجدوي الاقتصادية والاجتماعية والاستراتيجية لعملية فصل ومعالجة المونازيت

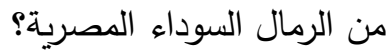

• ما الصناعات القائمة علي معدن المونازيت والعناصر المكونها لها؟ • مالاجراءات والاساليب التنظيمية المتبعة للحفاظ علي البيئه أثناء عمليات استخلاص الرمال السوداء وعمليات الفصل والمعالجة؟

\section{أهسا اهنم المهAه}

1-دراسة القيمة المضافة لفصل ومعالجة المونازيت. r-دراسة كيفية ربط عمليات الفصل والتثغيل بمجمل العمليات الاقتصادية والبيئية في ب-استتتاج أهمية القيمة المضافة في زيادة الثروة الوطنية وزيادة الخبرة المصرية.

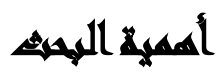

196

$$
\begin{aligned}
& \text { المجلد الخمسون، العدد الثاني، الجزء الرابع، فبراير اY • الترقيم الدولي 0826-0 } \\
& \text { ISSN 1110 }
\end{aligned}
$$


تظهر أهمية البحث في محاولة قياس القيمة المضافة لعمليات الفصل والتثغيل لمعدن المونازيت الذي يدخل في صناعات عديدة ويعتبر ثروة اقتصادية، وأيضًا الاستغلال الأمثل

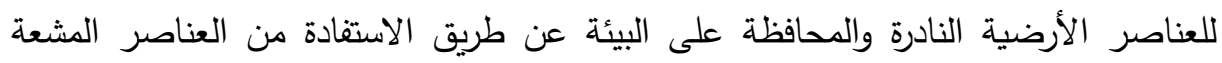
بالابحاث والدراسات بهئية المواد النووية والاستخدامات السلمية للمفاعلات النووية وامداد لبنهاد الثركة المصرية للرمال السوداء بمعادن الرمال السوداء وعناصر معدن المونازيت .

\section{هروضر المهنه}

الفرض الأول: هناك علاقة طردية ذات دلالة بين فصل وتثغيل المونازيت والقيمة الاقتصادية المضافة. الفرض الثاني: هناك علاقة ذات دلالة بين المعالجة الآمنة للمونازيت والمحافظة على البيئة والاستفادة من المواد المشعة في الاستخدامات السلمية للطاقة النووية. الفرض الثالث: هناك علاقة طردية ذات دلالة بين تثغيل المونازيت وتوطين الصناعات التكنولوجية الكبرى وخفض العجز في الميزان التجاري.

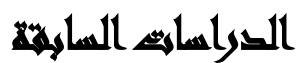

حمدي سيف النصر، كمال عبد الباقي: تقرير تقني عن التخطيط المستقبلي لمعالجة معدن

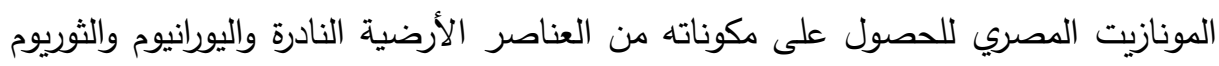

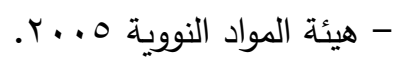

تهدف الدراسة لمراجعة وتدقيق معلومات بيت الخبرة الأجنبي الخاص بدارسة الجدوي

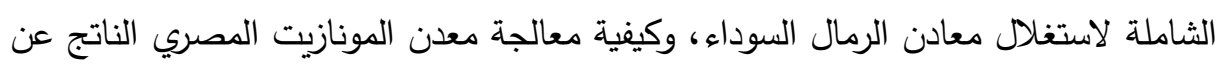
نشاط الثركة المصرية للرمال السوداء.

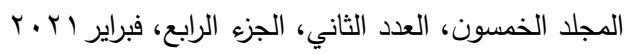

$$
\begin{aligned}
& \text { الترقيم الدولي 0826-0 1110 }
\end{aligned}
$$


وقد توصلت الدراسة إلى النتائج الآتية: إعداد التصميمات التقصيلية للمستوى الصناعي لمعالجة طن واحد من المونازيت. التأكد من البيانات المتوقعة من الشركة، وتدوير النفايات التهات وأنها مبنية على تجارب نصف صناعية أجرتها جهات دولية احترافية متخصصة في خامات الرمال السوداء. سحر أحمد حسن: الأهمية النسبية لقطاع التعدين في الاقتصاد القومي المصري دراسة

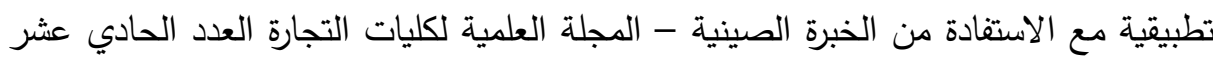

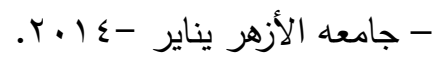
تهدف الدراسة لتفعيل البعد التتموي لقطاع التعدين، والحدّ من المشكلات البيئية للقطاع التعديني في مجال تلوث الهواء وتلوث التربة، وتعظيم الاستفادة من قطاع التعدين في تتمية الاقتصاد المصري وبالتالي زيادة القيمة المضافة للثروة المعدنية. وقد توصلت الدراسة إلى النتائج الآتية: أ- الاهتمام بقطاع التعدين يساهم في رفع معدلات التتمية الاقتصادية والاجتماعية في مصر .

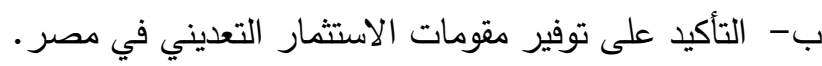

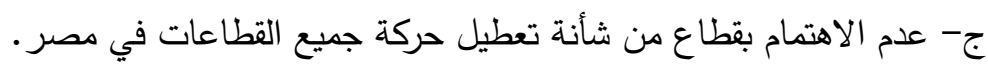
إبراهيم السيد زكريا: مدخل مُقترَح لاستخدام الضرائب في مكافحة التلوث البيئي في جمهورية مصر العربية دراسة ميدانية مجلة البحوث المالية والتجارية العددء كلية التجارة جامعة

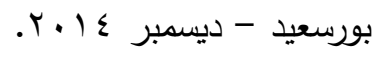

تهدف الدراسة إلى توفير بيانات مناسبة وموضوعية للتخطيط الاقتصادي لمكافحة التلوث البيئي من خلال تصميم معلومات محاسبية وبيئية، ومراجعة نظام الإدارة البيئية

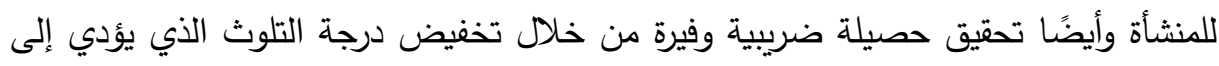

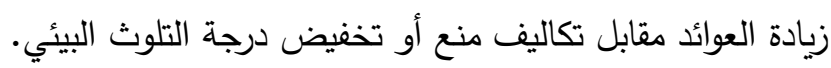

$$
\text { وقد توصلت الدراسة إلى النتائج الآتية: }
$$

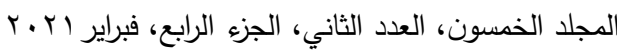

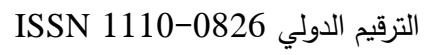


أ- إن حماية البيئة تعتمد بالدرجة الأولى على وعي أفراد المجتمع باعتبار أن التلوث بالدرجة

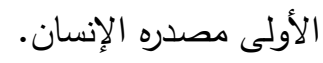

ب- إن الضرائب البيئية لا تؤدي إلى منع التلوث تمامًا وإنما إلى التوصل للحجم الأمثل للتلوث أو الحد المقبول منه.

ج- الإلمام بتجارب بعض الدول المتقدمة والنامية في معالجة التلوث البيئي بإبراز الخصائص البه الضريبية لمعالجة مشكلة التلوث.

سعاد صادق متولي: المتطلبات الاقتصادية والبيئية لمعالجة آمنة لمعدن المونازيت المصري دراسة تطبيقية بهيئة المواد النووية رسالة دكتوراه معهد الدراسات والبحوث البيئية، جامعة عين

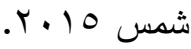

تهدف الدراسة إلى التعرف على التصنيف النوعي والكمي لأنواع المعادن الموجودة بالرمال السوداء بجمهورية مصر العربية، والاطلاع على الدراسة الفنية لعمليه الفصل والمعالجة ودور جهاز شؤون البيئة في وضع المعايير والمواصفات للمشروعات التعدينية. وقد توصلت الدراسة الى النتائج الآتية: أ- ليس هناك تعارض بين التتمية والمحافظه على البيئة حيث إن مشروع الدراسة يتم داخل

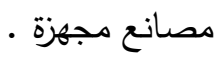

ب- - أشارت نتائج الدراسة إلى أوجة القصور في التكلفة الاقتصادية لمعالجة معدن المونازيت وفصل العناصر منة، وذلك بعد ما توسعت شركة الرمال السوداء بإنشاء مصنع إنه كبير يستوعب الاحتياطي الكبير من معدن المونازيت وذلك يؤدي إلى فقد جزء كبير من الموارد الطبيعية وإهدار أموال الدولة.

K. A. RABIE; N. M. ABDEL MONEM; B. EI_MONEM, I. M. ISMAIL, O. S. HELALY and E. SALAMAA

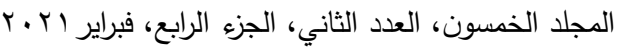

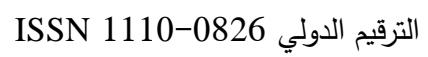


استخلاص العناصر الارضية النادرة من المونازيت المصري منخفض الدرجة باستخدام

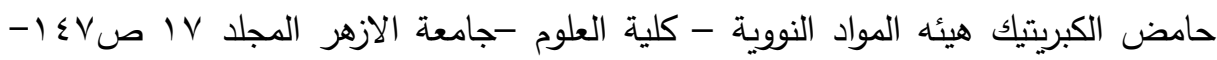

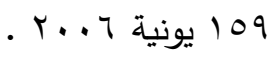

تهدف الدراسة إلى التوجه نحو إنشاء عملية بسيطة وغير مكلفة لهضم المونازيت

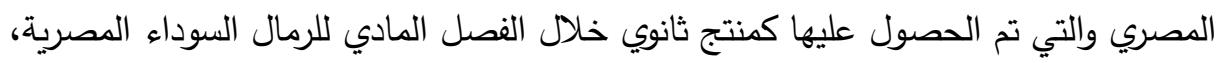

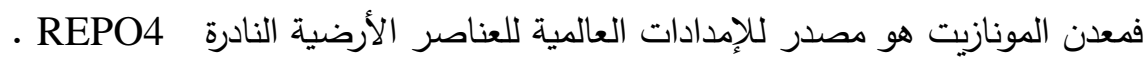
وقد توصلت الدراسة إلى النتائج الآتية: أ- إن معالجة المونازيت ذات أهمية كبيرة لأنها مصدر للإنتاج العناصرالأرضية النادرة وقد

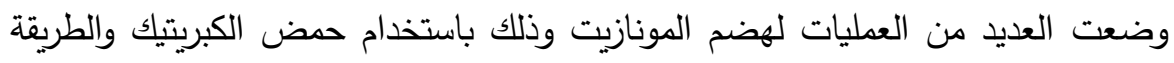
القلوية مع محلول هيدوكسيد الصوديوم.

ب- من الناحية التجارية لا تزال هناك طريقتان في المنشآت الصناعية لفصل المونازيت

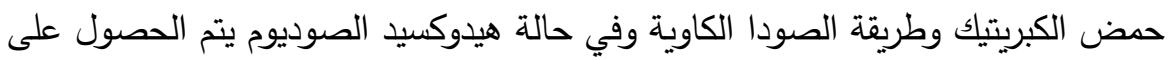

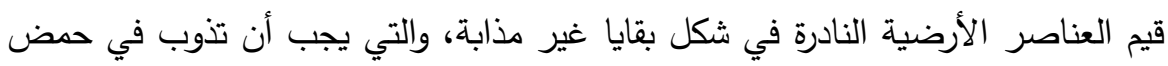

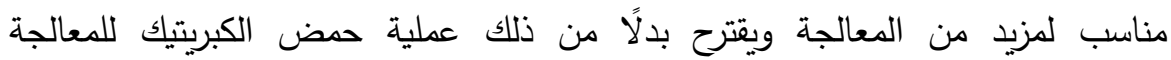

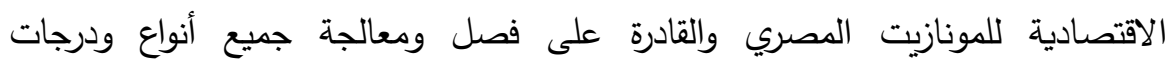
المونازيت، وستؤدي العملية إلى الحد من الآثار الخطرة الناشئة عن النشاط الإثعاعي

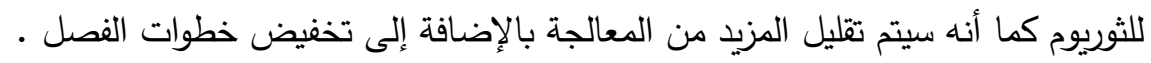

\section{Mohammed I. Moustafa:}

دراسات معدنية وجيوكيميائية لسلسة المونازيت وسيلكيات الثوريوم والعناصر الارضية النادرة

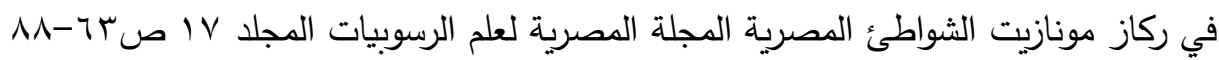

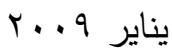


تهدف الاراسة إلي استخدام التركيز المائي بالجاذبية والفصل الكهروستاتيكي والفصل

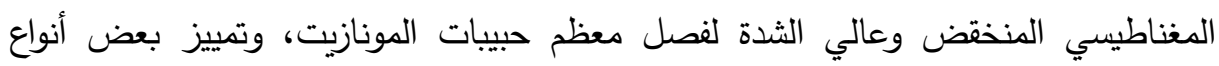
المونازيت الاخرى قليلة الوجود غير منتظمة الثكل عديمة اللون والوردية. توصلت الدراسة إلى النتائج الآتية:

أ- إنها تمكن من الحصول على ركائز المونازيت بدرجة نقاوة \9\% وبنسبة استرجاع كلية تساوي • ٪ عند استخدام التركيز المائي بالجاذبية والفصل الكهروستاتيكي والفصل المغناطيسي.

ب- يعتبر أكسيد السيريوم هو العنصر الأرضي النادر الأساسي في أنوع المونازيت المدروسة وبالنسبه لحبيبات المونازيت عديمة اللون والوردي.

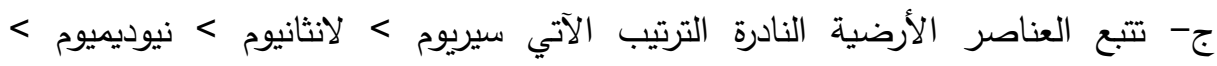
برازيديميوم > سماريوم > جاديلينوم > ديسبروسيوم.

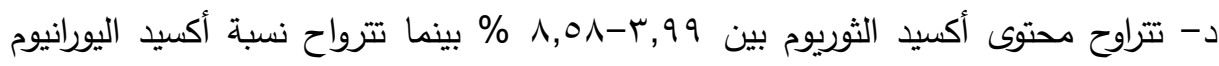
\% $1, v \varepsilon-11$.

Aziza Ibrahim Lutfi Abd Elfatah:

استخلاص اليورانيوم أثناء معالجة المونازيت المصري المنخفض باستخدام حامض الكبرتيك -

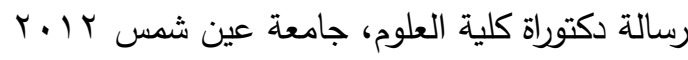

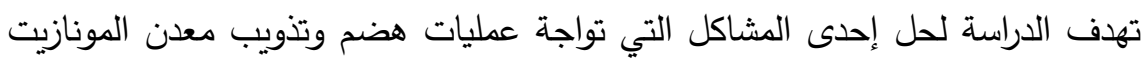
غير النقي •0\% وذلك لفصل مكوناته الرئيسية أثناء تطبيق هذة العمليات على المستوي الأعلى من المستوي المعملي، مع الوضع في الاعتبار أن عنصر اليورانيوم يوجد في الرمال

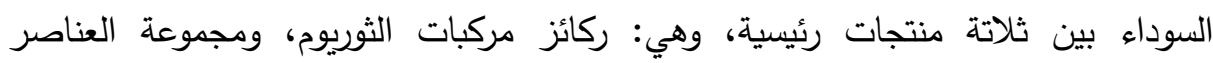
الأرضية النادرة، ثم اليورانيوم، فهناك هدف الحفاظ على أغلب محتوي اليورانيوم في اتجاة واحد لضمان سهولة وفاعلية الاستخلاص وتطهير العناصر ذات القيمة الاستراتيجية والاقتصادية

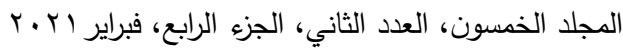

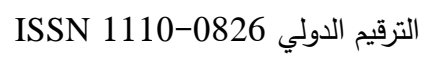


الأخرى مع الأخذ في الاعتبار المحاليل والكيماويات والوسائل والمعدات الضرورية لتحقيق

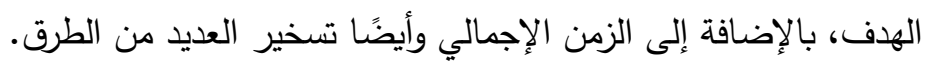

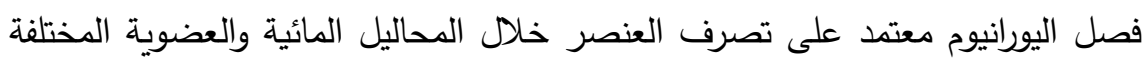
وكذلك ضبط العديد من طرق الفصل والتتقية لليورانيوم وتطبيقها منفردة أو متحدة للحصول على أعلى نقاوة. وقد توصلت الدراسة إلى النتائج الآتية: أ- فتح المونازيت بالحمض وتوصيف الطريقة وترسيب كل من اليورانيوم والثوريوم ومجموعة العناصر الأرضية النادرة. ب- زيادة كفاءة الترسيب لكلٍ من الثوريوم واليورانيوم ومجموعة العناصر الأرضية النادرة باستخدام محلول الكربونات للإذابة القاعدية.

Abdullah Muhammad Attiah:

التقيم البيئي لمنطقة شيد ساحل البحر المتوسط مصر، رسالة ماجستير كلية العلوم، جامعة

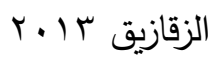

تهدف الدراسة إلى دراسة الرمال السوداء والتتييم البيئي لمنطقة رشيد لما تحتويه من

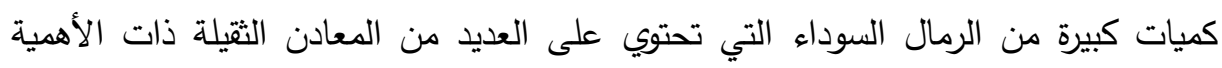

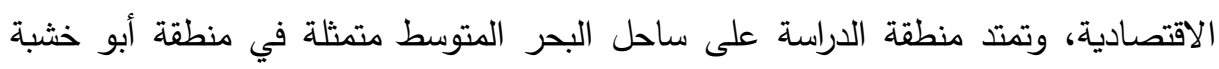
التي تتبع منطقة رشيد بمحافظة البحيرة. وقد توصلت الدراسة إلى النتائج الآتية:

أ- بعد تحليل عينات الرواسب الثاطئية ثبت تصوراً عن مدى اختلاف المعادن المتواجدة في

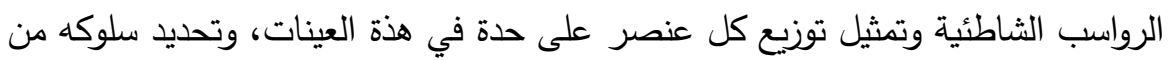

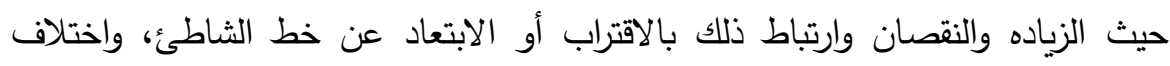
تركيزات هذة العناصر وأيضًا اختلاف سلوكها العام في توزيعها.

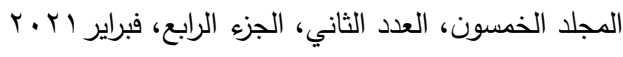

$$
\begin{aligned}
& \text { الترقيم الدولي 0826-0 الخيون }
\end{aligned}
$$


ب- تتثابه عينات الأصداف في نسب بعض العناصر التي تحتويها وتختلف بشكل واضح في محتواها لبعض العناصر الأخرى.

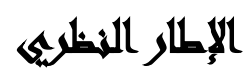

أولًا: أشكال الرمال السوداء: تتواجد رواسب الرمال السوداء على السواحل المصرية في

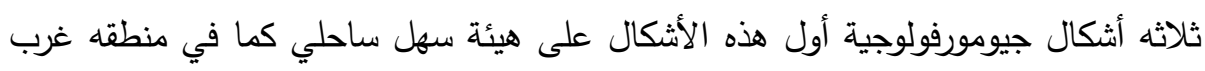

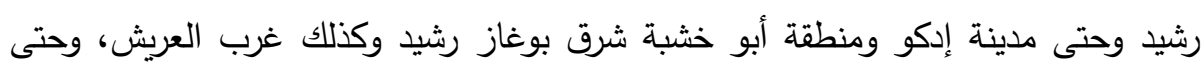

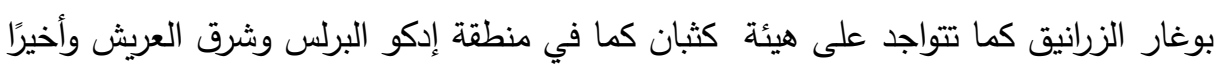

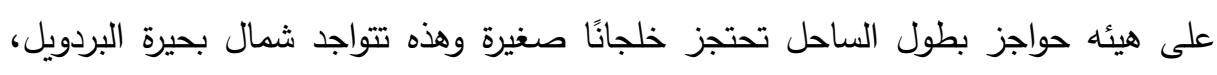

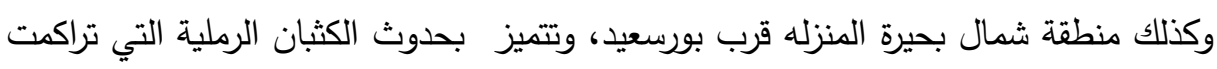

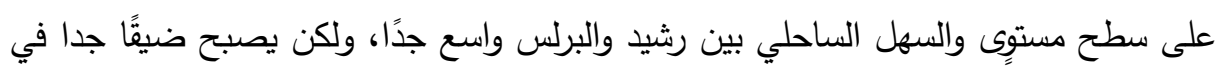

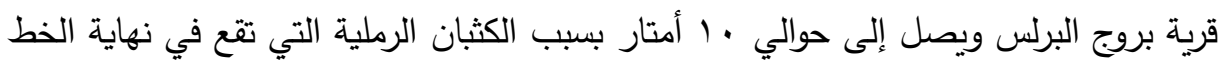

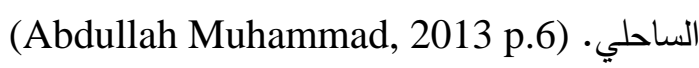
ثانياً: طبيعة الرمال السوداء : تعريف الرمال السوداء: هي رواسب رملية تتراكم على الثواطئ بالقرب من مصبات الأنهار

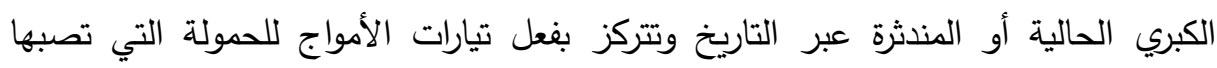

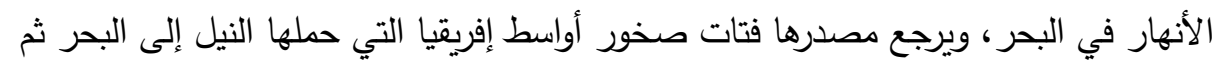
قامت الأمواج بنقلها إلى الساحل، حيث ترسبت معادن الرمال السوداء مختلطه برمال الثاطئوتعتبر ودائع رسوبية من المعادن الكثيفة التي تتراكم من الرمال والطمي والطين في ترئي

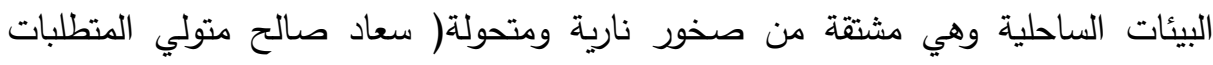


ثالثاً: التعرف على عناصر الرمال السوداء ومكوناتها: الرمال السوداء تتكون من عدة معادن والمعدن هو عبارة عن مادة صلبة متجانسة وغير عضوية بفعل عوامل طبيعية لها تركيب كيميائي محدد وترتيب ذري داخلي محدد، فالذرة هي أصغر جزء من من المادة وتتجمع الذرات مع بعضها البعض لتكوين العنصر وتتجمع العناصر مع بعضها البعض لتكوين

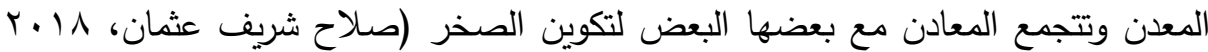

المعادن الإتصاديه بالرمال السوداء هي:

$$
\begin{aligned}
& \text { • معدن المونازيت (محل الدراسة) } \\
& \text { • • معدن الألمنيت }
\end{aligned}
$$

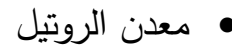

$$
\begin{aligned}
& \text { • • معدن الماجنتيت } \\
& \text { • • معدن الجارنت } \\
& \text { • معدن الزيركون }
\end{aligned}
$$

( ) تعريف معدن المونازيت ومكوناته PO4(Ce,La) Monazite: هو معدن من المعادن الاقتصادية بالرمال السوداء وكان قديمًا يُصنَّف علي أنه نفاية يتم التخلص منه نهائيا ويحتوي على عنصر اليورانيوم والثثريوم المشع وأكثر من 60\% من العناصر الأرضية

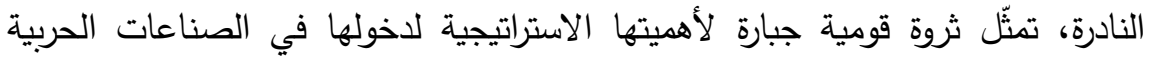

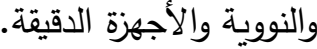

التركيب الكيميائي: فوسفات الفلزات الأرضية النادرة خصوصًا السيريوم واللانلثوم والأيتريوم

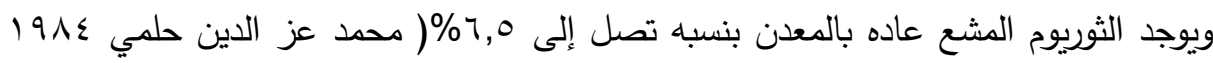


r) تعريف معدن الألمنيت ومكوناته FeTio3 Limenite : معدن الألمنيت من العناصر

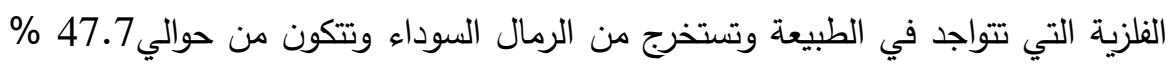

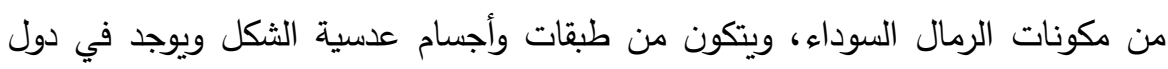

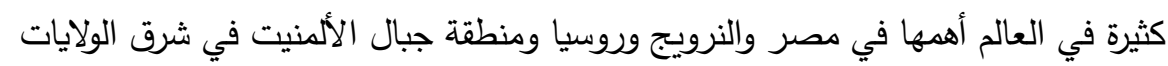

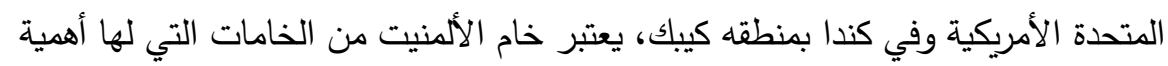
في صناعات استراتيجية كبرى حيث تستخدم في هياكل الطائرات وسبائك الصلب وفي بعض صناعات الورق والبلاستيك والبويات والمنسوجات وفي تبطين وتغليف أنابيب نقل

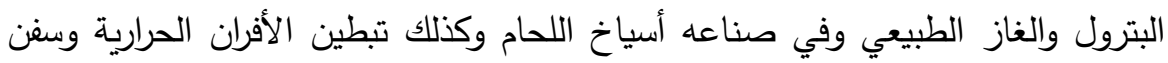

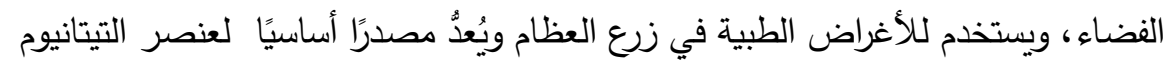
الذي يدخل في تصنيع الطائرات نظرًا لأنه يتمتع بصلابة عالية ووزن خفيف (محسن

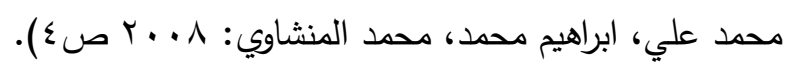
r) تعريف معدن الروتيل ومكوناته TiO2 Rutile: يتواجد الروتيل غالبًا في الصخدور المتعرضة للحرارة العالية كالصخور النارية والصخور المتحولة، ويكون لونه شفاف يميل

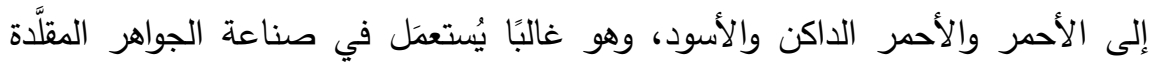

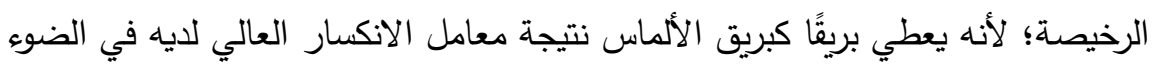

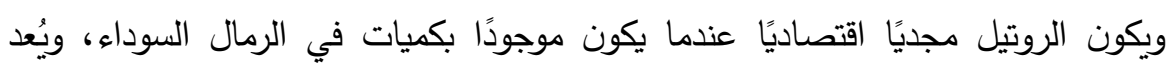

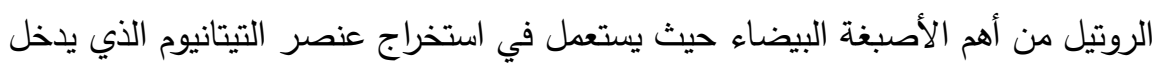

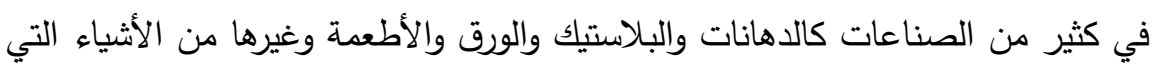
تتطلب ألوانًا مشرقة بيضاء.

§) تعريف معدن الماجنتيت ومكوناته Fe3O4 Magnetite هو أحد الخامات التي لتيفاء يستخلص منها الحديد ويستخدم في صناعة المغناطيس الدائم، ويعد هذا المعدن أحد أكاسيد الحديد وهو أسود اللون ولامع وكثافته عالية، وينتج من تأثير عوامل التعرية

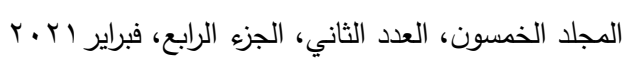

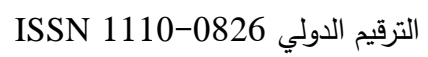


للصخور النارية والمتحولة، ويتكون الماجنتيت من الصخور النارية والمتحولة ومن أهم الخامات التي تستخرج منه الحديد ويدخل في صناعه الصلب ولا ينصهر إلا على درجة ولنة

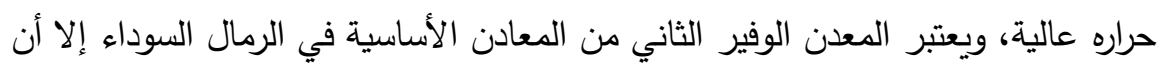

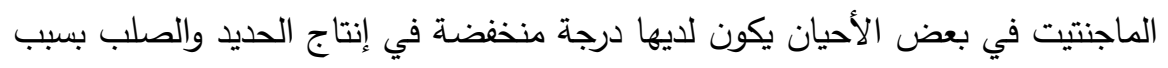
احتوائها على الشوائب وخاصه الكروم والفاناديوم. 0) تعريف معدن الجارنت ومكوناته X3Y2(SiO4)3 Garnets يحتوي رواسب الرمال

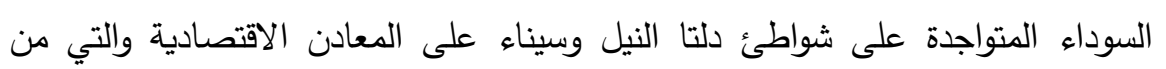
ضمنها الجارنت، وأثناء إجراء عمليات الفصل والتركيز للمعادن الاقتصادية يمكن فصل الجارنت لمنتج أساسي أو ثانوي، وبدراسة الخواص الفيزيائية والكميائية والتركيب المعدني

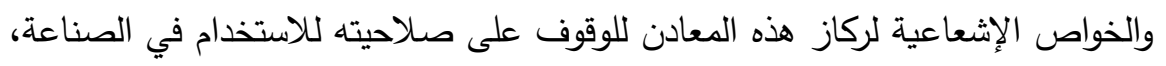

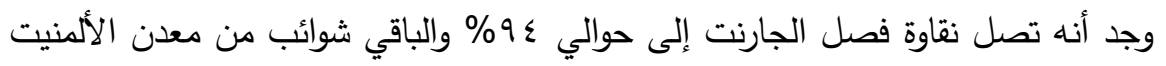
والسيلكات الخضراء ونسبة السيلكا الحرة في الركاز منعدمة لعدم احتوائه على الكوارتز

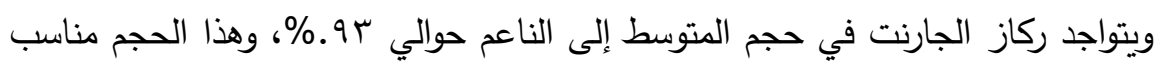
في صناعة اسطونات القطع والصنفرة ومعظم حبيبات الجارنت شبة زاوية ومستديرة وهذه ميزة للاستخدام المرشح في فلاتر المياه

(Ayman A. Halawa and Kandil M. kandil: 2009 p.117) وأيضًا يتكون معدن الجارنت من مجموعة سيكليات الحديد الألمنيوم مع تركيب كيميائي يتميز بمجموعة عناصر سليكات، واللون يختلف حسب التركيب الكميائي ولكن تكثر فيه الألوان الحمراء ويتمتع الجارنت بخصائصه المناسبة للاستعمالات الصناعية، مثل: أغلفة الكثط لورق الصنفرة وفي تجهيز المطاط والبلاستيك والزجاج ويستخدم بعض أنواع الجارنت

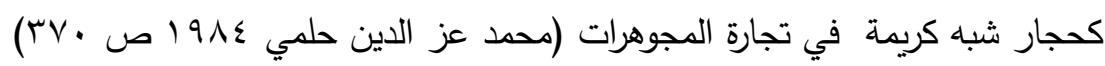


7) تعريف معدن الزيركون ومكوناته ZrSiO4 Zircon معدن الزيركون من المعادن الثائعة الواسعة الانتشار في جميع أنواع الصخور النارية ويحتوي الزيركون على العناصر المشعة التهن،

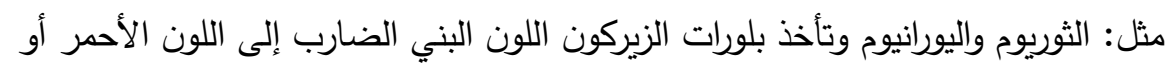

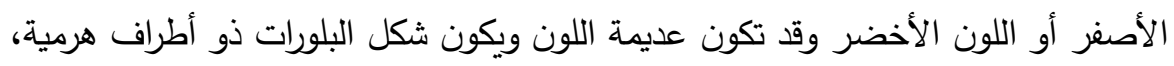
ويقوم الانحلال للزيركون بفعل العوامل الجوية؛ ولهذا فهو يوجد أيضًا في الحصى والرمال

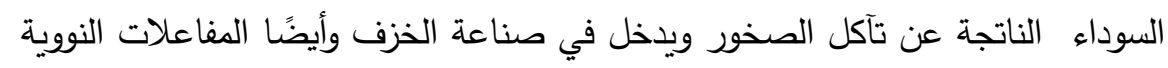
وصناعة الألماس الاصطناعي ويوجد على هيئة حبيات مستديرة في رمال الثواطئ النهرية والبحرية، مثل: رمال شاطئ رشيد ودمياط وكذلك رمال شواطئ استراليا والبرايل

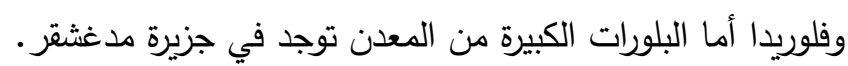
رابعاً: التعرف على المونازبت: معدن المونازيت PO4(Ce,La) (محل الدراسة) هو معدن من المعادن الاقتصادية بالرمال السوداء، يتبلور المعدن في فصيلة الميل الواحد نظام المنشور البلورات نادرة وعادة صغيرة جدًا ويوجد المعدن على هيئة كتلة حبيبية (الرمال)

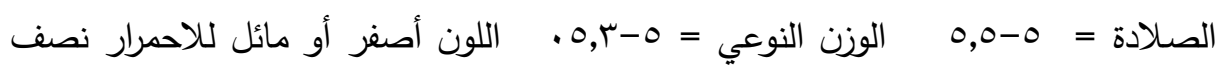

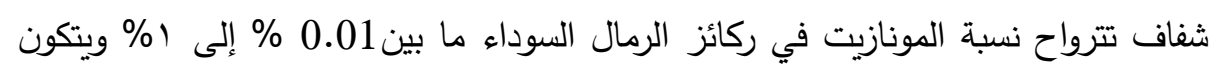

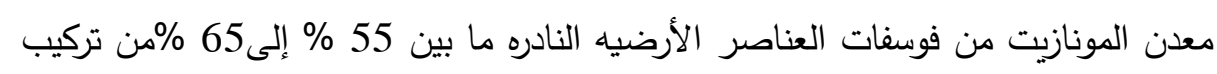

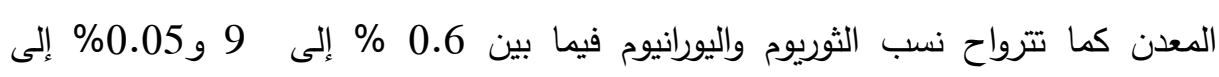

لا يتواجد المعدن بمفرده ويعتبر معدن المونازيت نادرًا نسبيًا حيث يوجد في الصخور الجرانيتية والرواسب الرملية الناتجة من تفتت الصخور ويتركز المعدن في هذه الرواسب الرئ الرملية

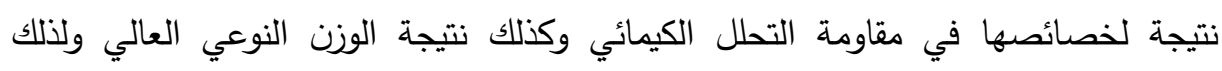
يصاحبة معادن أخرى تقاوم التحلل، مثل: الماجنيت والألمنيت والروتيل والزيركون، وتعتبر التئه سواحل البرازيل والهند من أكبر مصادر الإانتاج العالمي للمعدن وفي جمهورية مصر العربية

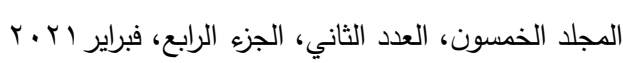

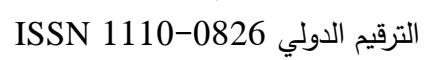


يوجد على شاطئ البحر المتوسط في رشيد ودمياط والبردويل وأيضًا سواحل البحر الأحمر،

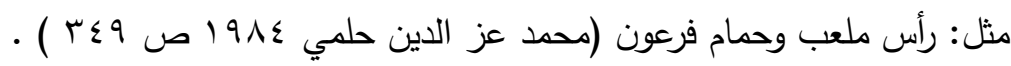

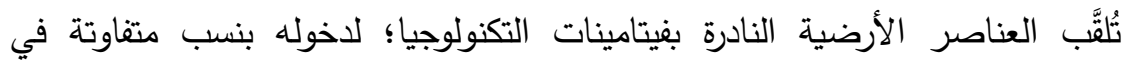

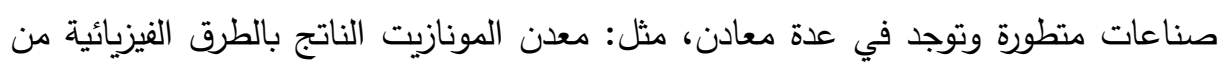

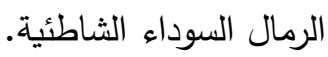
خامساً: العناصر الأرضية النادرة وإستخداماتها: يتم فصل المعادن الاقتصادية عن بعضها البعض بالطرق الفيزيائية باستغلال الفروق الواضحة في خواصها وقابليتها للتوصيل الكهروستاتيكي؛ حيث يمكن بهذه الطريقة فصل المعادن بصورة شبه كاملة. واستغلال هذه الرمال وتحويلها إلى منتجات اقتصادية تقدر بملايين الدولارات، ولا يكلف من الناحية التكنولوجية سوى بعض الأجهزة التي تعمل على فصل رواسب هذه الرمال التقيلة

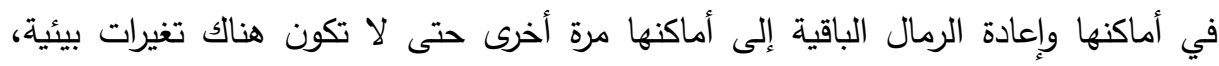

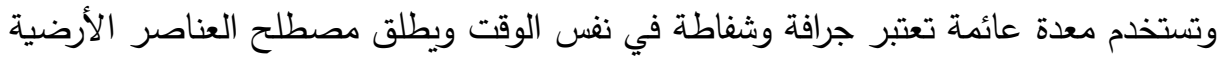

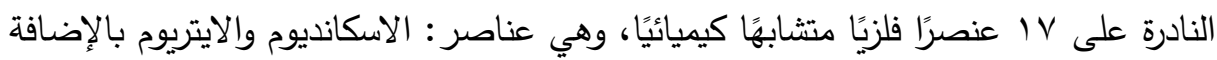

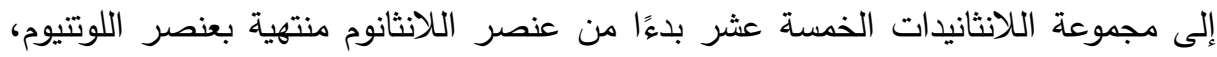
وتتميز هذه المجموعة بالتثابه الحاد بين أفرادها بحيث إنها تتصرف كوحدة واحدة، وهذة

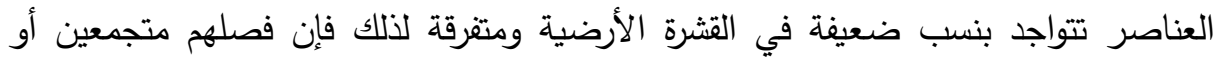
منفردين للاستخدام البحثي أو الصناعي يعتبر أهم مواضع التحدي في عالم التقنيات الحديثة، والعقود الماضية شهدت الأسواق العالمية زيادة في الطلب على العناصر الأرضية النادرة؛ نتيجه لاتساع نطاق التطبيقات المستخدمة في هذة العناصر بصورها المختلفة، وتمثل النخاع الشوكي للتصنيع التكنولوجي الحديث معدني وغير معدني حيث تستخدم في جميع مراحل

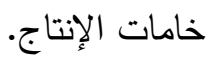
- السبائك الصلب، والستيل، والمواصلات بجميع أنواعها، وإنتاج الطاقه بأثكال متعددة. 208

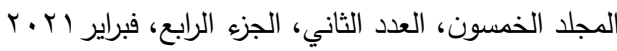

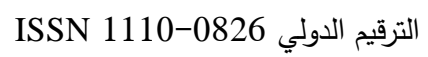


- تكرير البترول، أجهزة الليزر، والأشعة، فوق البنفسية وتحت الحمراء، والعدسات، وواقيات

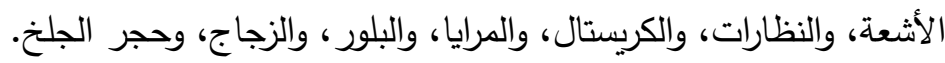

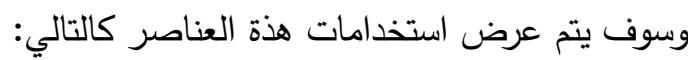
1-الأسكانديوم: يضاف إلى مصابيح بخار الزئبق ليبدو الضوء أشد وإطارات الدراجات الهوائي. r-الأيتريوم: في صناعه الألوان في كثير من أنابيب الصور التليفزيونية، ويستخدم في أفران الميكرويف ويقوي السراميك. r-اللانثانيوم: يدخل في صناعة مصابيح قوس الكربون في الأفلام، ويستخدم في البطاريات.

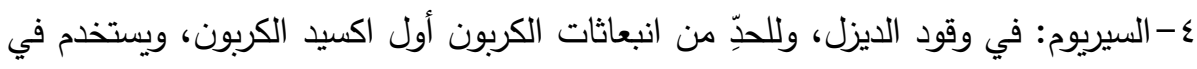
تلميع الزجاج.

0- البرازديميوم: يستخدم مع الماغنسيوم لجعل معادن محركات الطائرات عالية القوة. 1- النيوديميوم: يستخدم في المغناطيسات القوية خفيفة الوزن، والسيارات صديقة البيئة.

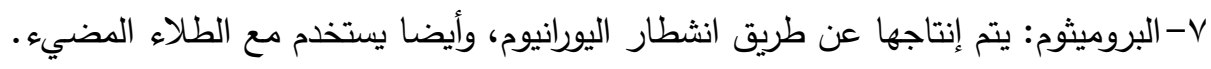

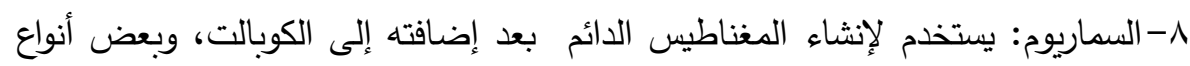
الزجاج.

9-الأيروييوم: يستخدم لعقود في الفوسفور الأحمر في مجموعات، وشاشات الكمبيوتر. • 1- الجادولينيوم: يتسخدم في قضبان التحكم في الدحطات النووية، والتطبيقات الطبية. 11- التيرييوم: مع نظم السونار المتطور وأجهزة الاستثعار الإلكتروني. r ا- الديسبروسيوم: يستخدم في بعض أنواع أجهزة الليزر الأخضر.

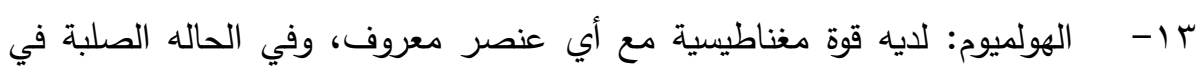
الليزر - الت

ـ ا- الأربيوم: يستخدم كعامل تصفية الفوتوغرافية ومكبر الصوت.

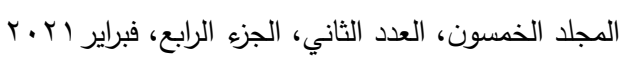


1 - الثوليوم: يستخدم في بعض أجهزة الليزر الجراحية، وفي مجال تكنولوجيا الأشعة

السينية.

ד ا- الأيتربيوم: يستخدم في أجهزة قياس الزلازل، والمنشطات في كابلات الألياف

البصريـة.

V - ا الليوتيتيوم: يستخدم في حساب عمر النيزك، أو أداء التصوير المقطعي بالإصدار

البوزيتروني PET بالإشعة.

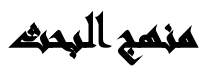

تعتمد الدراسة على الدنهج الوصفي الاستقرائي لتحديد جغرافيا الأماكن التي ترتكز عليها

الرمال السوداء، والمنهج التحليلي والتطبيقي.

يشمل البحث على إطار نظري يعتمد على الدراسة العملية للمراجع والرسائل والدوريات

ذات الصلة وأبحاث هيئه المواد النووية في الفصل والمعالجة.

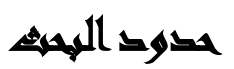

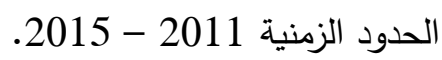

الحدود الدكانية: رواسب الرمال السوداء وتكنولوجيا الفصل والمعالجة لمعدن المونازيت بهيئة

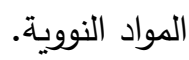

\section{إلجراءائ المهثه}

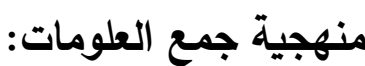

أولاً: تحديد البيانات المطلوبة: وذلك من أجل تحقيق أهداف البحث ثم تحديد البيانات

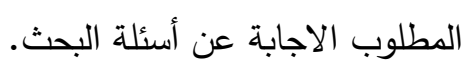

$$
\begin{aligned}
& \text { المجلد الخمسون، العدد الثاني، الجزء الرابع، فبراير اY · TSN }
\end{aligned}
$$

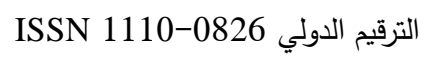


ثانياً: تحديد الجهات المنؤط بها توفير البيانات: أن الدراسة تطبيقية بهيئة المواد النووية وذلك

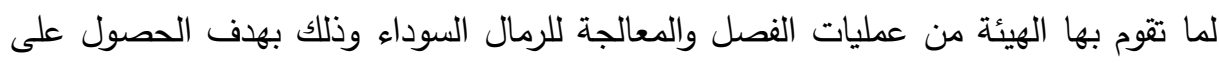
اليورانيوم والثوريوم المشع والقيام بالدراسات العلمية المعملية لتحديد الطريقه المناسبة للوصول إلي أعلي نقاوة للمعدن المونازيت والعناصر الارضية النادرة. ثالثاً: مخاطبة الجهة بثكل رسمي للحصول علي البيانات: بعمل خطابات معتمدة إلي رئيس

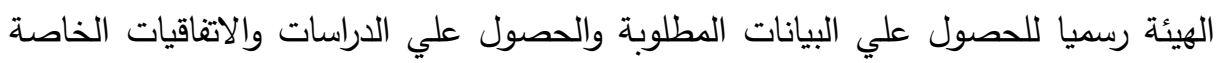
بالاستغلال الرمال السوداء والحصول علي المجلدات العلمية ذات الصلة

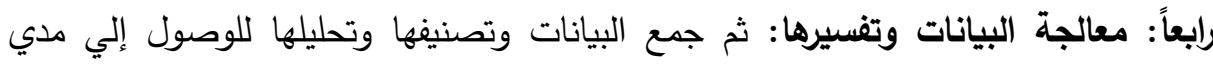

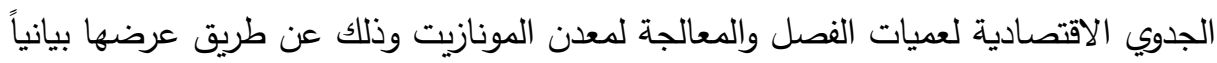
ووتعسيرها واستخلاص النتائج بالاستتاد للبيانات الرسمية لجمهورية مصر العربية لصادرات

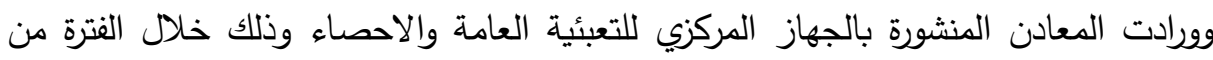

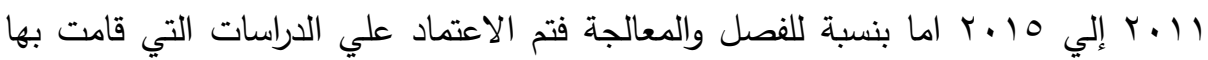

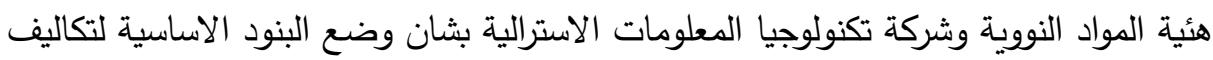
البحث والتتقيب والفصل والمعالجة للرمال السوداء للحصول علي معدن المونازيت .

\section{نمائيج الهميث}

دراسة البعد التنموي للقطاع التعديني للمعادن على المستوي الاقتصادي أولاً: نظرة عامة على الميزان التجاري في مصر: كثف تقرير من الجهاز المركزي للتعبئه

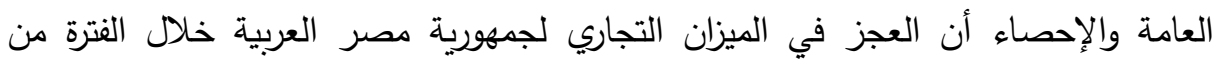

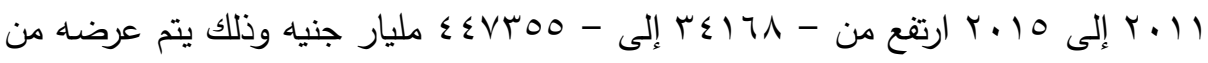

خلال جدول رقم (1).

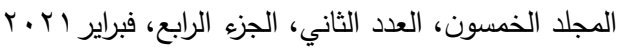

$$
\begin{aligned}
& \text { الترقيم الدولي 0826-0 التيوني }
\end{aligned}
$$


وبصورة أكثر وضوحًا فإن تعريف الميزان التجاري لأي دولة: هو الفرق بين قيمة

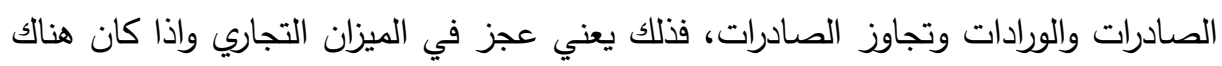
زيادة في الصادرات وتراجع في الورادات هنا يكون للدولة (فائض تجاري)

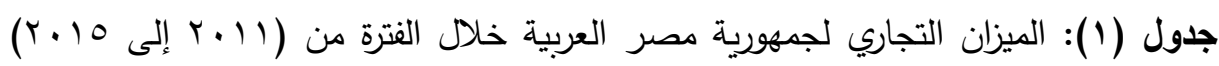
(بالمليار جنيه)

\begin{tabular}{|c|c|c|c|c|}
\hline الميزان التجاري & الصادرات & الواردات & السنة & م \\
\hline $111.90-$ & INATO. & $r V \mid \leq \varepsilon 0$ & $r .11$ & 1 \\
\hline ro017V- & 1人тV79 & $\varepsilon \varepsilon 1947$ & $r . I r$ & $r$ \\
\hline Y07ाI $\leq-$ & 199111 & $\leqslant 00990$ & $r .1 r$ & $r$ \\
\hline 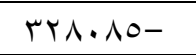 & $190 Y V 7$ & ודצחס & $r .1 \leq$ & $\varepsilon$ \\
\hline$\varepsilon \ldots \wedge T \vee-$ & $171 . V V$ & $0719 \leq \leqslant$ & $r .10$ & 0 \\
\hline
\end{tabular}

المصدر : نشرة وزارتي التجارة والصناعة

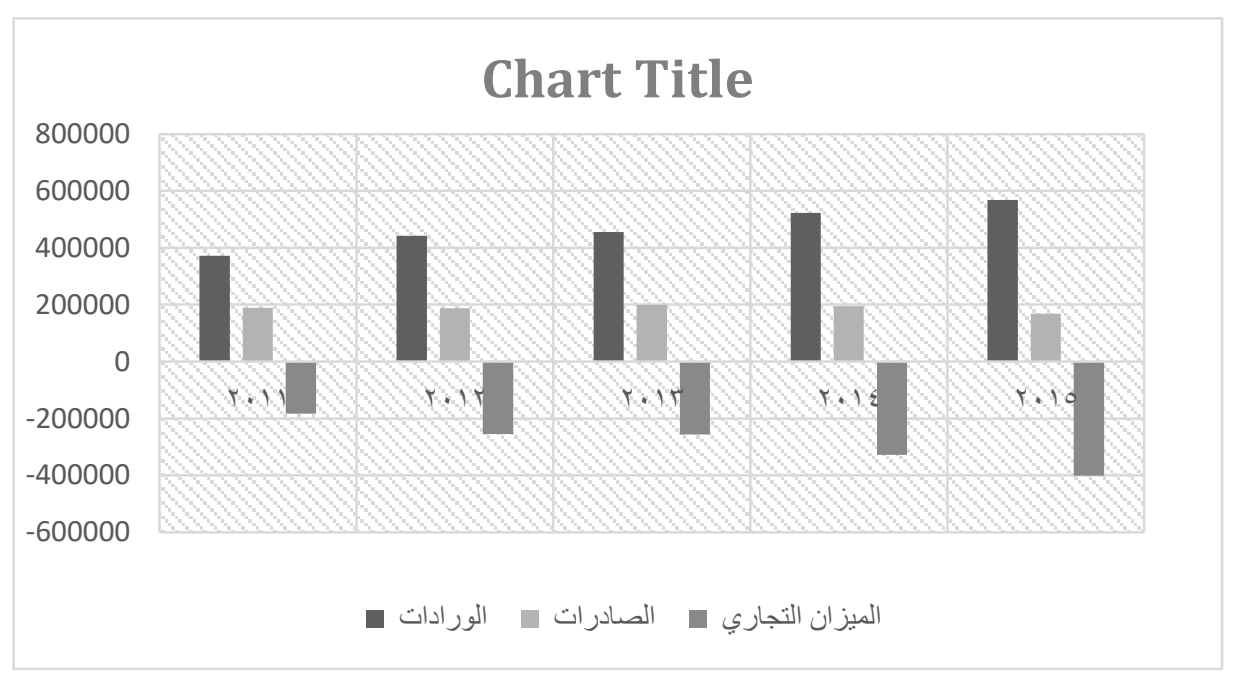

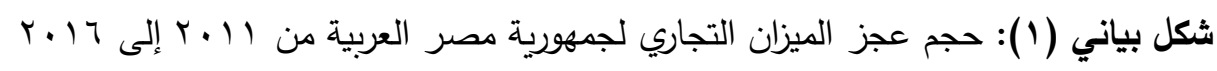

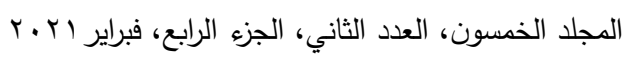

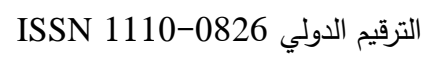


في إطار ما سبق وكما هو موضح بالثكل رقم ( (1) نجد أن هناك ضرورة لخفض العجز

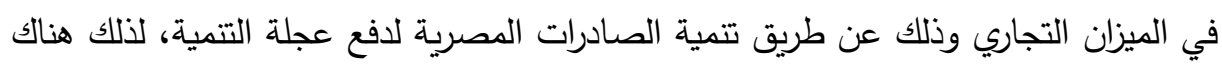
دور ضروري ومؤكد ينبغي القيام به للتأكيد على إمكانية تحقيق الأهداف من خلال آليات

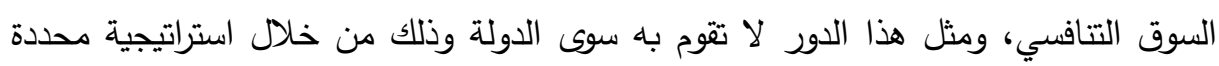

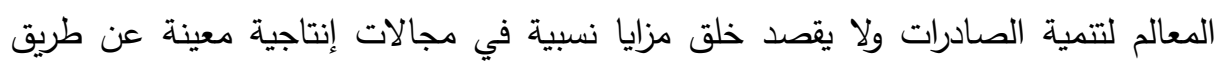

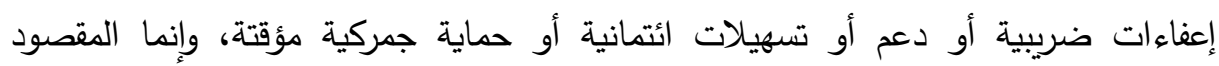

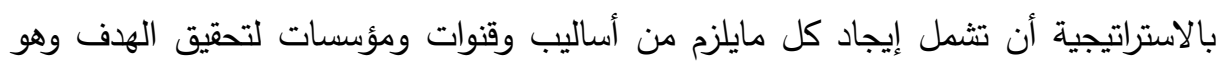

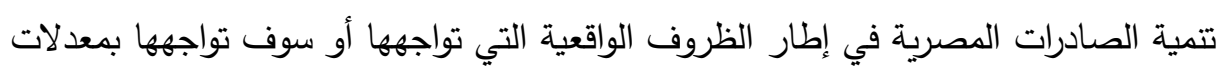

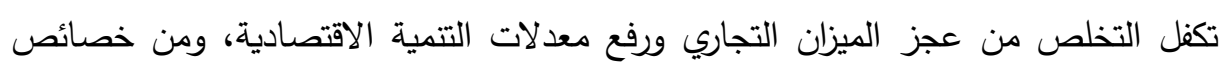

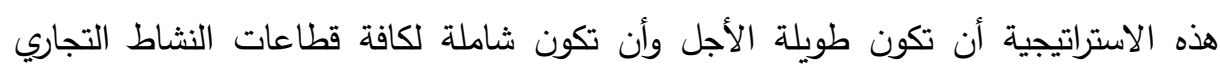

والاقتصادي والتشابكات القائمة بينها. وتتضح أهمية التصدير في قدرته على ما يلي:

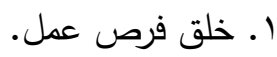
r. إصلاح العجز في الميزان التجاري وبالتالي ميزان المدفوعات باعتبارها أخذ الموارد الرئيسية للنقد الأجنبي مما يؤثر بصورة مباشرة على التوازن المالي والاستقرار النقدي

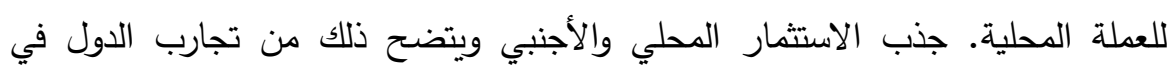
التصدير وأهمية دور الاستثمار كمرك أساسي لنجاح عملية التصدير ومثال لتلك الدول: تونس، وتركيا، والصين، وكوريا الجنوبية حيث أسهم الاستثمار في زيادة الانتاجية وإنشاء الإحلية 
مجلة العلوم البيئية

معهد الدراسات والبحوث البيئية - جامعة عين شمس لئية

جهاد سعيد السيد وآخرون

ثانيًا: الأهمية النسبية للصادرات التعدينية في مصر :

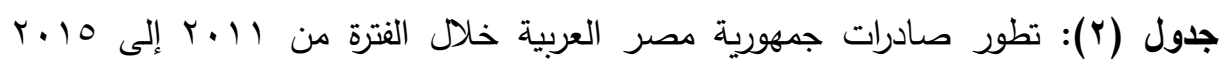

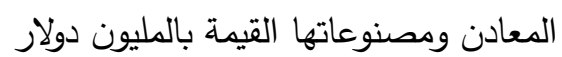

\begin{tabular}{|c|c|c|c|c|c|}
\hline$Y .10$ & $r .1 \varepsilon$ & $r .1 r$ & $r .1 Y$ & $r .11$ & اسم الاولة \\
\hline YAY,. T & r & $r v \cdot, q \varepsilon$ & rov,. & $\varepsilon \wedge r, 7 r$ & إيطاليا \\
\hline 101,19 & $17 \cdot, 19$ & 117,94 & $1 \cdot 7, \varepsilon$ & $11 \leq, \wedge \wedge$ & الجمهوريـة الجزائرية \\
\hline $\mathrm{VO,Yq}$ & $09, \wedge \varepsilon$ & 99,91 & $11 r, r$ & 111,50 & الجمهورية السودانية \\
\hline$V 1, \wedge \varepsilon$ & $\vee \wedge, 70$ & $i r \wedge, \vee$. & $1 \cdot v, 9$ & 100,Ar & تركيا \\
\hline or, r & 90,19 & $19 \cdot, r \varepsilon$ & $v 7, V$ & 19,זч & المملكة الأردنية \\
\hline OY,YO & 09,71 & 119,11 & $9 \wedge, \vee$ & lov,rV & الجمهورية اللبنانية \\
\hline $01, M_{1}$ & $79, Y 1$ & Vr,Yq & $V r, \Lambda$ & $\Lambda \varepsilon, O V$ & ألمانيا \\
\hline$\Sigma \eta, \cdot r$ & VT,YO & 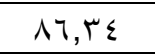 & $00, r$ & $\vee ०, \cdot \wedge V$ & المملكة المغربية \\
\hline$r q, r$. & 07,100 & $\sum q, \vee 1$ & $V \cdot r$ & $1 r \leq, \cdot \Lambda$ & الجمهوربة العربية السوربة \\
\hline$r v, \varepsilon r$ & $\sum \wedge, 00$ & $V \cdot, 10$ & $71, r$ & $01, V$. & الجمهورية العراقية \\
\hline$r \eta, V$. & ro,rv & $r \cdot, \mu^{\prime}$ & $r 0,9$ & $r_{1, \varepsilon q}$ & هولندا \\
\hline ro,rr & $r \cdot, r r$ & 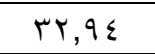 & ov, & $1 \cdot \cdot, r$ & الإمارات العربية المتحدة \\
\hline$r \varepsilon, \cdot V$ & $0 \leqslant, Y T$ & $\vee \vee, \wedge q$ & $\wedge q, r$ & $170, r V$ & إسبانيا \\
\hline rT,ז & $r \varepsilon, \lambda T$ & YO, YT & $\varepsilon \varepsilon, \wedge$ & $\varepsilon V, r T$ & قطر \\
\hline$r \cdot, 00$ & & $1, \cdot r$ & $17, \varepsilon$ & $1, \ldots$ & تايلاند \\
\hline $19,7 r$ & 19,10 & 19,77 & $r q, r$ & $r, Y q q$ & كينيا \\
\hline $17, V T$ & $\varepsilon q, \wedge \wedge$ & 10,0r & IYA, $\varepsilon$ & o9,0r & الجماهيرية اللبيية \\
\hline $1 \pi, 09$ & $r \varepsilon, \varepsilon q$ & $r \varepsilon, \cdot 9$ & $r \cdot, \Lambda$ & $r, r$. & الولايات المتحدة الأمريكية \\
\hline $1 \leqslant \leqslant 0, \wedge \leqslant$ & $19 \leq 9, r 7$ & ro9.,71 & Yo..,00 & TITI,IT & إجمالي الصادرات \\
\hline
\end{tabular}

المصدر: الجهاز المركزي للتعبئه العامة والإحصاء (بيانات تم تبويبها ومعالجتها بقطاع نقطه التجارة

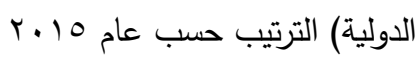

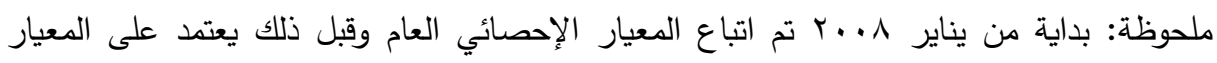
الإحصائي الخاص. باص. 
ولصادرات المعادن أهمية في تحسين الميزان التجاري، ولذلك يجب العمل على تتمية وتوفير البيئة الاستثمارية الملائمة لتثجيع القطاع الخاص وذلك بوضين التئع سياسة اقتصادية ثابتة لاعم القطاع الخاص من خلال منح قروض وتسهيلات ائتمانية وتقديم يد العون والمساندة لضمان نجاح واستمرار الاستثمارات الخاصة وتوسيع حاجه السوق المحلي من المعادن وتصن

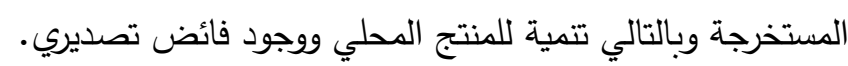

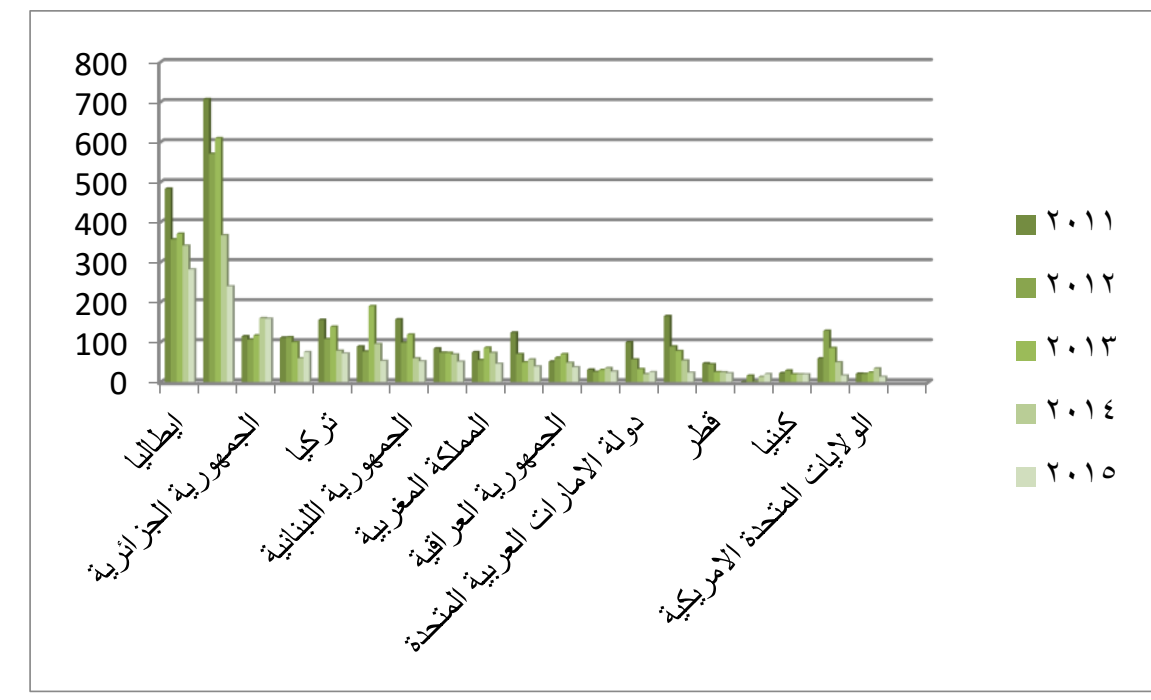

شكل بياني (r): حجم تطور الصادرات لجمهورية مصر العربية من المعادن ومصنوعاتها

$$
(r \cdot 10-r \cdot 11)
$$

ويتضح من الجدول رقم (r) والثكل البياني رقم (r) أن هناك انخفاض كبير في حجم

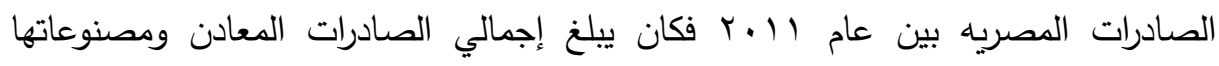

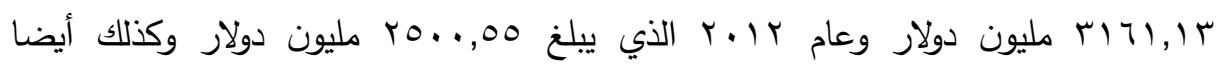

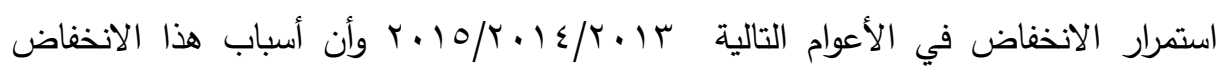
ترجع إلى تحول بعض دول العالم إلى الاستفادة من استخراج وفصل المعادن للحد من

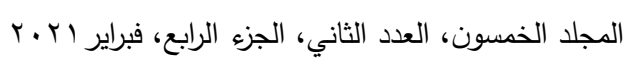

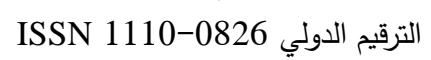


الاستعانة بالدول الأخرى ومساهمة في زيادة النشاط الافتصادي ومن جانب آخر تحفيز

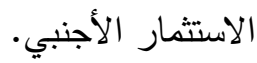

ثالثًا: الأهمية النسبية للورادات التعدينية للمعادن في مصر :

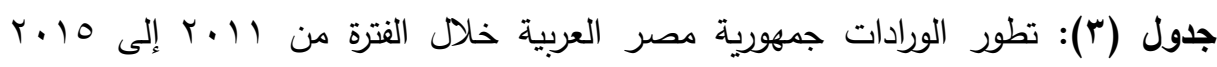
المعادن ومصنوعاتها القيمة بالمليون دولار جيهية

\begin{tabular}{|c|c|c|c|c|c|}
\hline$r .10$ & $r .1 \leq$ & $r .1 r$ & $r .1 r$ & $r .11$ & اسم الدولة \\
\hline ror, rit & $1 \cdot \wedge \wedge, 0 \wedge$ & $V 70, \cdot 1$ & $\wedge \neg \varepsilon, \varepsilon$ & $71,4,90$ & جمهورية الصين الشعبية \\
\hline $1 \cdot r V, V \leq$ & ITr & 1 Tos, 1 & $1 \leq 07,7$ & $\Lambda \wedge r, v$. & جمهورية أوكرانيا \\
\hline$V Y \varepsilon, O V$ & $0 . r, 07$ & $\Sigma \mid \Lambda, 1 Y$ & $70 V, \varepsilon$ & $V Y \cdot, T Y$ & تركيا \\
\hline$\Upsilon \wedge Y, V \varepsilon$ & $7.1,99$ & rvq,... & $\leqslant V \cdot, q$ & rqA,r. & جمهورية روسيا الاتحادية \\
\hline $090, \varepsilon$. & VAl, N & $90 r, 7$. & $91 \cdot, 9$ & $1 \cdot \leq 0,70$ & الولايات المتحدة الأمريكية \\
\hline 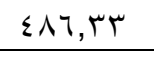 & $09 \cdot, 0$ & سו, & rus,r & 711,94 & إيطاليا \\
\hline$\leq \leqslant T, 11$ & $0 . v, 01$ & orq, vq & $\leq 7 r, \Lambda$ & rut,... & ألمانيا \\
\hline$r \leq 7, \vee \vee q$ & $M r, r T$ & $1 \mathrm{H}, 0 \mathrm{~V}$ & r & IVA, rV & كوريا الجنوبية \\
\hline$r$ rq,Ar & דr, & r & rᄉ & $r \leq 7,7 r$ & بلجيكا \\
\hline IVV, IV & rVA, ,0 & Tr,NI & rVA,O & $r V V, r$. & المملكة المتحدة \\
\hline$|V T, Y|$ & $1 Y 9, \leqslant \varepsilon$ & 107,87 & $\mid r \varepsilon, 1$ & $Y, T, 7 \leq$ & 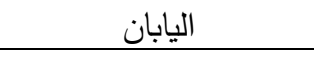 \\
\hline $18 \cdot, 17$ & 100,11 & $17 \varepsilon, \varepsilon r$ & $117, \mathrm{~V}$ & 19,19 & الهند \\
\hline $10 \pi, \cdot 1$ & $1 v \cdot, 1 T$ & rMA, r & $19 \leq, 0$ & $I V \varepsilon, V T$ & فرنسا \\
\hline$M r, \varepsilon \Lambda$ & ITr,VV & $1 \leq r, .9$ & $V r, \Lambda$ & $1 Y q, q r$ & بلغاريا \\
\hline $11 \wedge, \vee 1$ & $94, Y_{0}$ & $|\leq r, V|$ & $1 \mathrm{HO}_{\mathrm{N}}$ & ITr, E & المملكة العربية السعودية \\
\hline 110,07 & $9 \Lambda, \vee \vee$ & 108,07 & $r \cdot \varepsilon, \cdot$ & ror, NI & زامبيا \\
\hline $9 \varepsilon, 94$ & 90,09 & 94,17 & $V r, V$ & $\Lambda \cdot, r \varepsilon$ & الإمارات المتحدة \\
\hline $9 \cdot, \cdots$ & VT, T. & $\leqslant 7, Y_{0}$ & r & $\varepsilon 7,1 \vee$ & البحرين \\
\hline$\wedge) \vee, \varepsilon q$ & AOYO, MI & ArVT, $\varepsilon \varepsilon$ & $\wedge \wedge \wedge 0, \wedge 9$ & $1.01,91$ & إجمالي الورادات \\
\hline
\end{tabular}

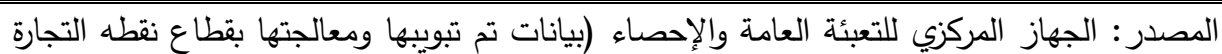

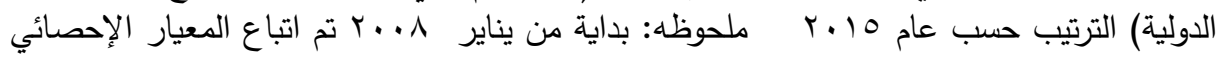


ويتضح من الجدول رقم (r) أن هناك زيادة في واردات المعادن ومصنوعاتها نجد أن

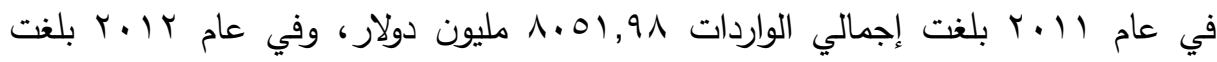

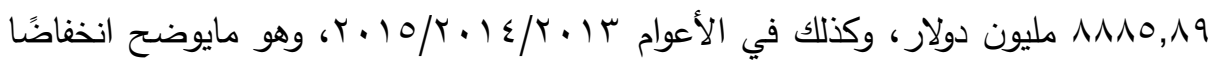
الصادرات أيضًا وبالنظر إلى عجز الميزان التجاري، وبتحليل لبند المعادن فقط نجد أن زيادة

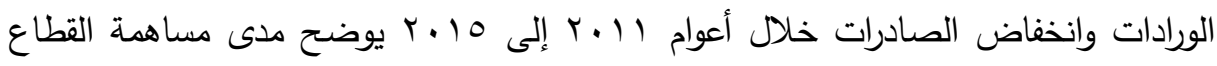

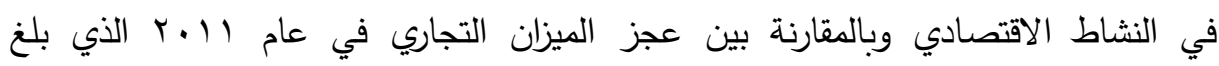

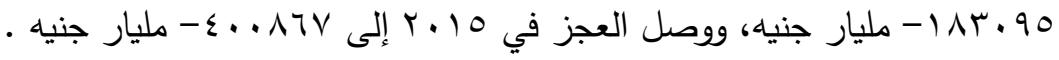

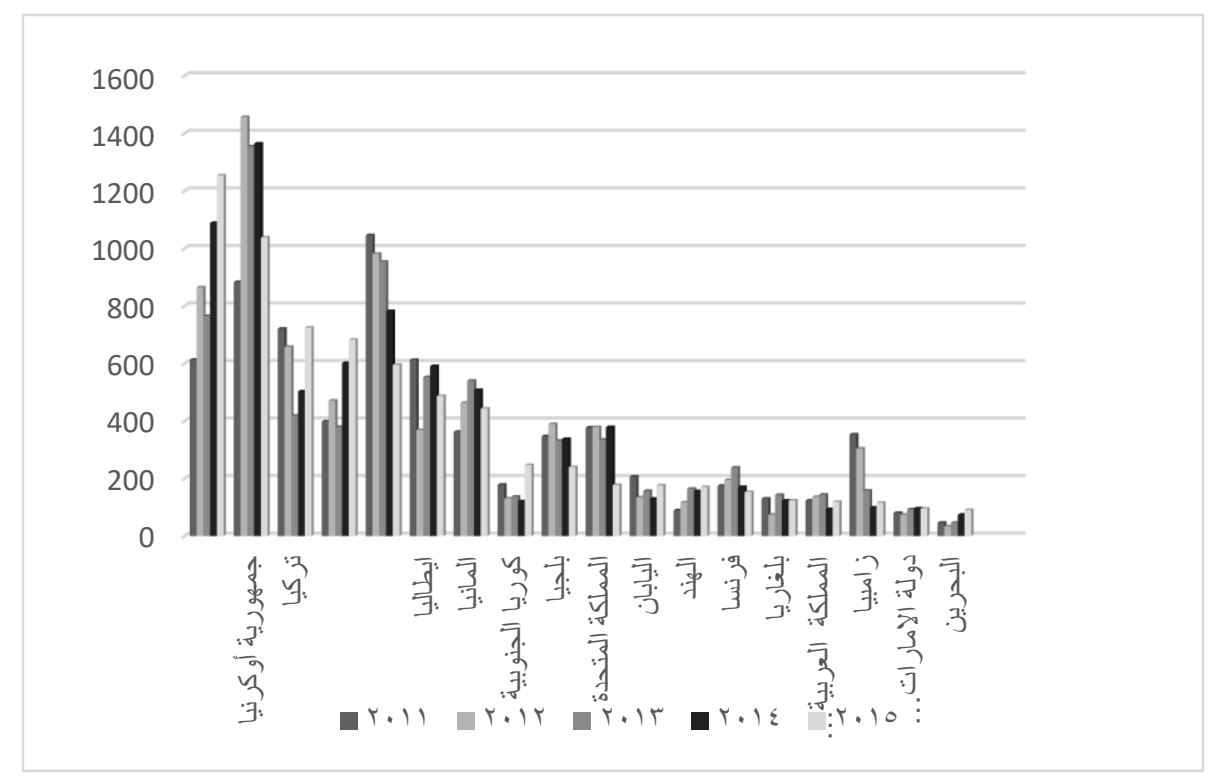

شكل بياني (r): تطور الواردات لجمهورية مصر العربية للمعادن ومصنوعاتها لبعض الدول

$$
(r \cdot 10-r \cdot 11)
$$

رابعًا: مساهمة القطاع التعديني والاستخراجي للمعادن من التوظيف: استخراج وفصل المعادن يعبر عن طبيعة المشروعات التعدينية التي تقوم على كثافة رأس المال أكثر من كثافة

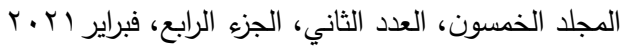

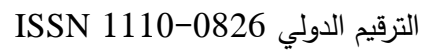


العمالة وهذا يوضح أن تاثير زيادة العمال وإن كان يعمل على تحسين المناخ الاقتصادي ورفع مستوي المعيثة للأفراد إلا أنه تأثيرها ليس ككثافة رأس المال، فمساهمة رأس المان المال كأحد

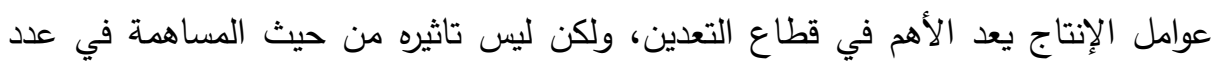

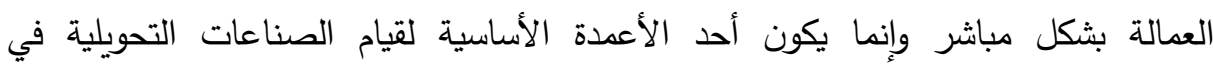

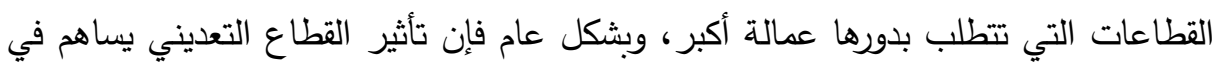

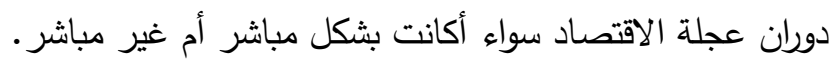
جدول (؛): الإنتاج الصناعي في منشآت القطاع الخاص (عدد المنشآت - جملة المشتغلين

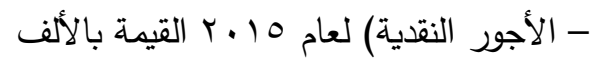

\begin{tabular}{|c|c|c|c|}
\hline الأجور النقدية & المشتغلين & المنشآت & البند \\
\hline $\begin{array}{l}\varepsilon \cdot r Y V \\
r \cdot r \wedge \leq r \\
r Y V V .\end{array}$ & 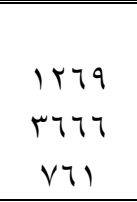 & $\begin{array}{l}1 \\
\varepsilon 1 \\
\varepsilon\end{array}$ & 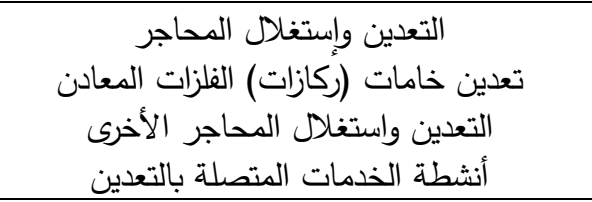 \\
\hline $\begin{array}{l}\text { rAVTAY. } \\
\text { r.VOATr } \\
\text { AOVITV }\end{array}$ & 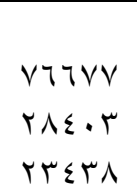 & $\begin{array}{l}7 \cdot V \\
V I \\
r \cdot r\end{array}$ & 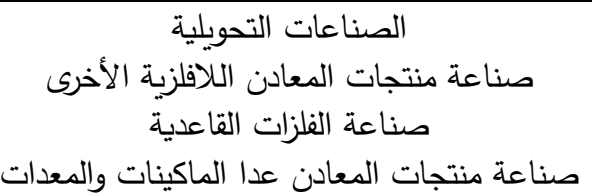 \\
\hline$V \cdot V O V 19$ & $|r \leqslant Y| \leqslant$ & $1 . r 7$ & الإجمالى \\
\hline
\end{tabular}

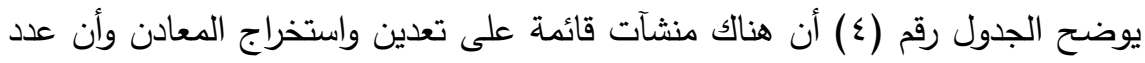

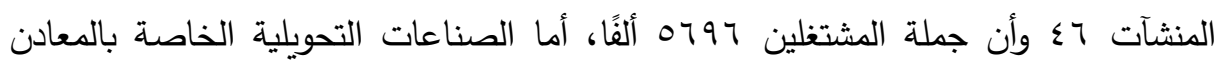

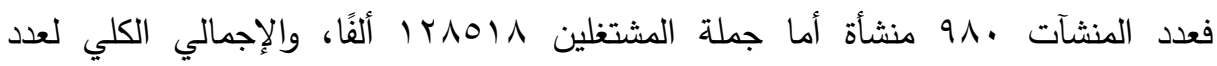

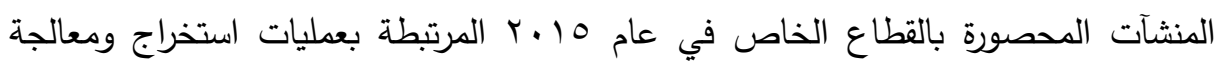

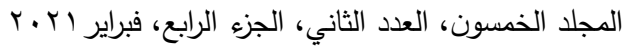

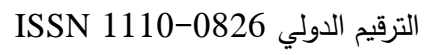




$$
\begin{aligned}
& \text { مجلة العلوم البيئية } \\
& \text { معهد الدراسات والبحوث البيئية - جامعة عين شمس لبس } \\
& \text { جهاد سعيد السيد وآخرون }
\end{aligned}
$$

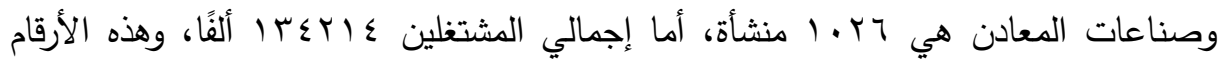

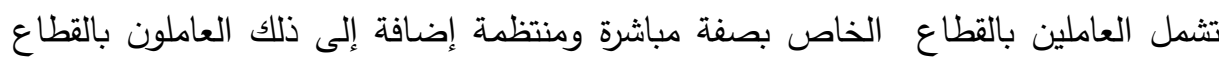
العام والمراكز البحثية والجيولوجية المختصة بالمعادن بصفة مباشرة أو غير مباشرة. خامسًا: حجم العائدات المتوقعة من فصل ومعالجة الرمال السوداء المصرية: وبهاء وبها يتم

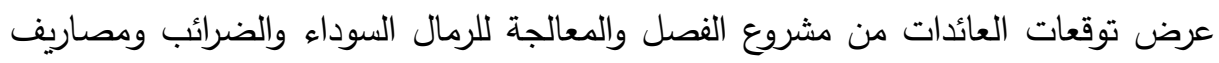

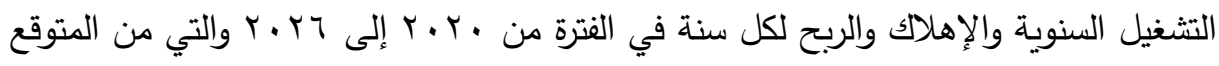

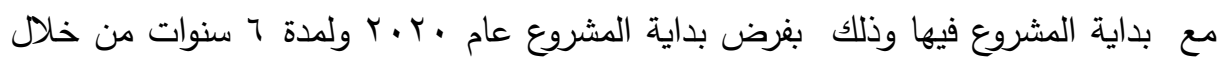

جدول رقم (0) - (0) 
مجلة العلوم البيئية

معهد الدراسات والبحوث البيئية - جامعة عين شمس له

جهاد سعيد السيد وآخرون

جدول (•): توقعات العائد الوراد من مشروع فصل ومعالجة الرمال السوداء والضرائب

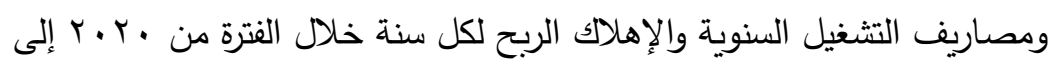

Tr ب r مليون جنيه

\begin{tabular}{|c|c|c|c|c|c|c|c|c|c|c|}
\hline 它 & 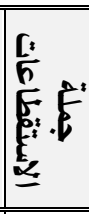 & $\underline{E}$ & $\begin{array}{l}E . \\
E \\
E \\
E \\
E\end{array}$ & $\frac{\underline{E}}{E^{2}}$ & 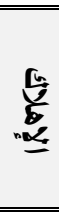 & 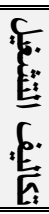 & 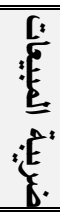 & 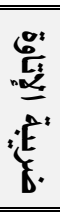 & 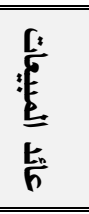 & $\underline{E}$ \\
\hline & & & & & & & & & - & $\dot{z}$ \\
\hline & & & & & & & & & . & $\begin{array}{l}3 \\
\dot{y}\end{array}$ \\
\hline & & & & & & & & & - & $\dot{0}$ \\
\hline 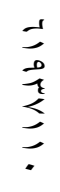 & $\begin{array}{l}0 \\
0 \\
\overrightarrow{1} \\
\overrightarrow{0} \\
0 \\
1 \\
\dot{1} \\
i\end{array}$ & $\begin{array}{l}\overrightarrow{1} \\
\overrightarrow{0} \\
\underline{z} \\
0\end{array}$ & $\begin{array}{l}0 \\
0 \\
m \\
z \\
z \\
z\end{array}$ & $\begin{array}{l}3 \\
m \\
1 \\
1 \\
z \\
z\end{array}$ & $\begin{array}{l}\leq \\
0 \\
0 \\
0 \\
1 \\
\leq\end{array}$ & $\begin{array}{l}5 \\
a \\
0 \\
1 \\
0 \\
1\end{array}$ & $\begin{array}{l}a \\
u \\
0 \\
a \\
m\end{array}$ & $\begin{array}{l}+ \\
\vdots \\
\vdots \\
\vdots\end{array}$ & $\begin{array}{l}1 \\
1 \\
0 \\
1 \\
a \\
0\end{array}$ & $\dot{\imath}$ \\
\hline $\begin{array}{l}\overrightarrow{0} \\
\overrightarrow{0} \\
1 \\
m \\
m \\
m\end{array}$ & $\begin{array}{l}? \\
\vdots \\
m \\
m \\
\vec{j} \\
⿱ 亠\end{array}$ & $\begin{array}{l}0 \\
0 \\
0 \\
c \\
m \\
m \\
m\end{array}$ & $\begin{array}{l}a \\
m \\
\dot{z} \\
\dot{z}\end{array}$ & $\begin{array}{l}u \\
\vdots \\
0 \\
0 \\
\vdots \\
i\end{array}$ & 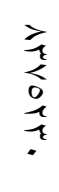 & $\begin{array}{l}1 \\
0 \\
a \\
1 \\
0 \\
\dot{1}\end{array}$ & $\begin{array}{l}< \\
\leq \\
0 \\
0 \\
\geq\end{array}$ & $\begin{array}{l}3 \\
0 \\
3 \\
3 \\
?\end{array}$ & $\begin{array}{l}z \\
3 \\
z \\
0 \\
3 \\
?\end{array}$ & $\dot{u}$ \\
\hline $\begin{array}{l}\overrightarrow{0} \\
0 \\
\dot{0} \\
0 \\
0 \\
1\end{array}$ & $\begin{array}{l}\geq \\
\overline{1} \\
0 \\
0 \\
0 \\
0\end{array}$ & $\begin{array}{l}\overrightarrow{0} \\
0 \\
\vdots \\
\vdots \\
0 \\
1 \\
1\end{array}$ & $\begin{array}{l}1 \\
1 \\
z \\
\leq \\
1 \\
1\end{array}$ & $\begin{array}{l}= \\
3 \\
3 \\
0 \\
0 \\
3 \\
1\end{array}$ & \begin{tabular}{l}
2 \\
\multirow{1}{*}{} \\
0 \\
$x$ \\
$z$ \\
$x$
\end{tabular} & $\begin{array}{l}3 \\
\vdots \\
\vdots \\
\vdots \\
\dot{z} \\
0\end{array}$ & $\begin{array}{l}\leq \\
\leq \\
1 \\
\frac{1}{\leq} \\
y\end{array}$ & $\begin{array}{l}3 \\
3 \\
3 \\
\underline{1} \\
0 \\
>\end{array}$ & 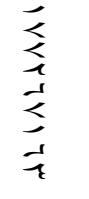 & $\dot{u}$ \\
\hline
\end{tabular}

220

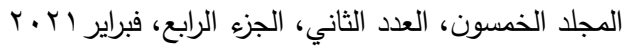

$$
\begin{aligned}
& \text { الترقيم الدولي 0826-0 1110 119 }
\end{aligned}
$$


مجلة العلوم البيئية

معهد الدراسات والبحوث البيئية - جامعة عين شمس له

جهاد سعيد السيد وآخرون

تابع جدول (•): توقعات العائد الوراد من مشروع فصل ومعالجة الرمال السوداء والضرائب

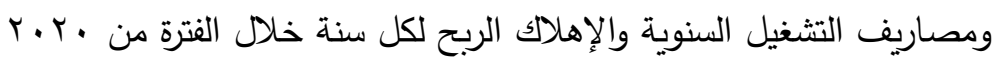

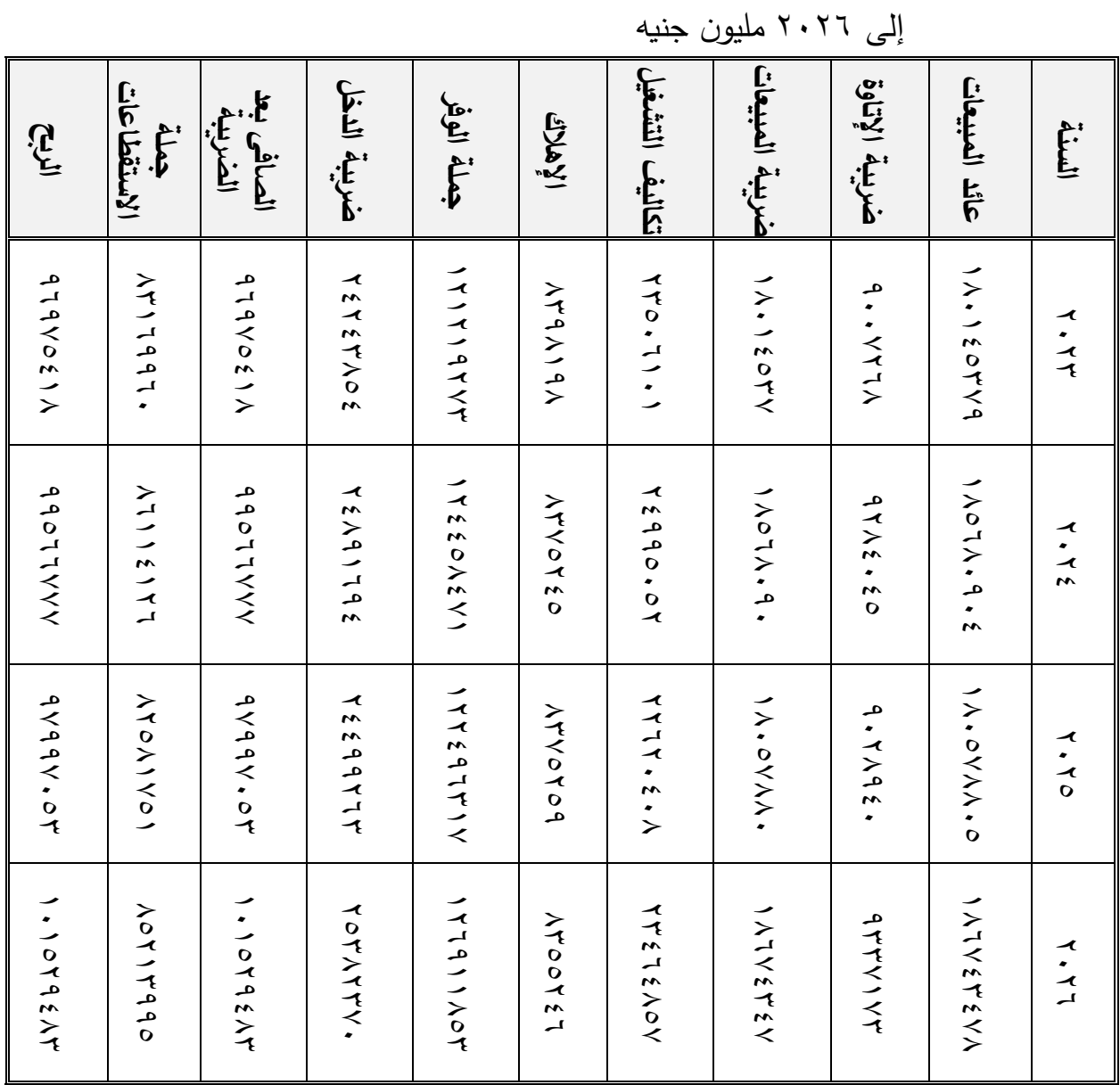

المصدر: حمدي سيف النصر الملخص التنفيذي لدراسة الجدوى الثاملة لاستغلال الرمال السوداء بكثبان البرلس مرجع سابق

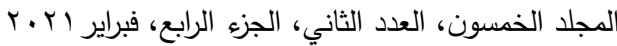

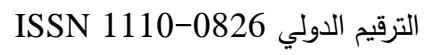


والقيمة الاقتصادية المضافة تعبر عن الفرق بين المدخلات المادية الجارية للمشروع الاستثماري ومخرجاته باستبعاد الإهلاك السنوي، مما سبق نجد أن عائدات المبيعات المتوقعة لهن

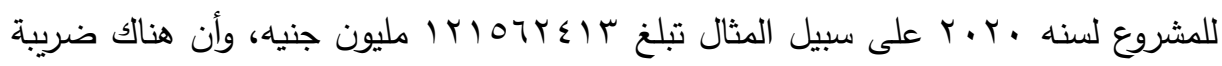

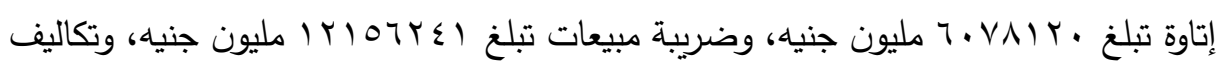

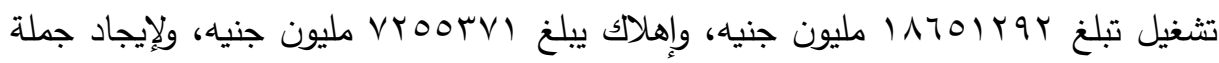

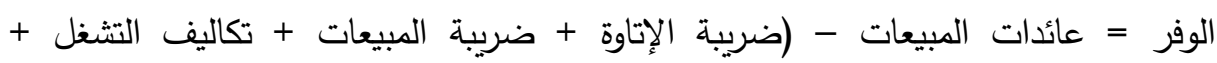

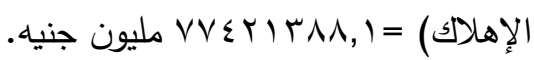

جملة الاستقطاعات = ضريبة الإتاوة + ضريبة المبيعات + تكاليف التشغيل + الإهلاك +

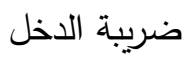
الربح = عائدات المبيعات - جملة الاستقطاعات

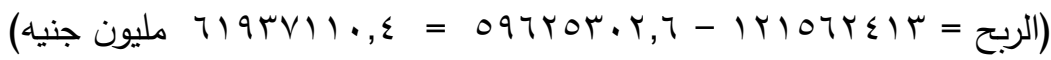

\section{نمائي المهيث}

استهدفت هذة الدراسة القيمة الاقتصادية المضافة لعمليات الفصل والمعالجة وتثغيل المونازيت من الرمال السوداء وذلك بالتطبيق على هيئة المواد النووية.

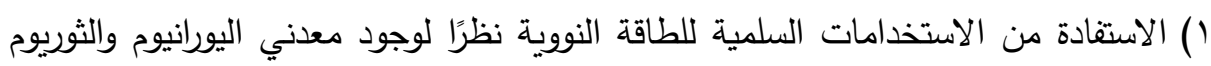

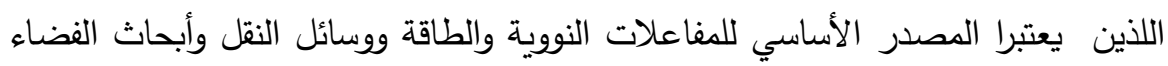
وأيضًا الزراعة والطب.

r) وضع أسلوب لمواجهة التلوث الناتج عن الفصل والمعالجة بالتتسيق مع الجهات المعنية ووزارة البيئة.

r) إن فصل ومعالجة معدن المونازيت يوفر الاحتياجات الإنتاجية والاستهلاكية ويقلل من التبعية والاعتماد على الخارج، ويعتبر مصدرًا لقطاعات الصناعات التحويلية الأخرى.

$$
\begin{aligned}
& \text { المجلد الخمسون، العدد الثاني، الجزء الرابع، فبراير ا Y. F }
\end{aligned}
$$

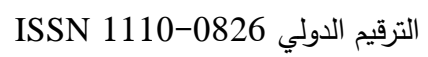


ع) تلبية احتياجات السوق المحلي من معادن الرمال السوداء.

0) سد النقص في احتياجات المحافظة والمحافظات المجاورة من الرمال النظيفة اللازمة لأغراض البناء والتشييد وصناعات الطوب الرملي.

4) عمليات التتقيب واستخراج المعادن في منطقة البرلس بمحافظة كفر الثيخ لها مردود اجتماعي وإنعاش اقتصادي ويتمثل ذلك في الاهتمام بأهالي المنطقة في أولوية العمل بالمشروع ورفع المستوى المعيشي بالمحافظة بالكامل.

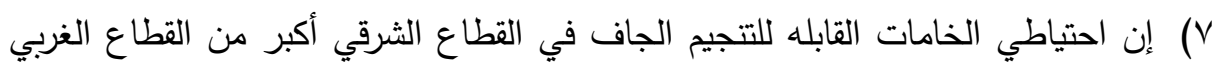
في منطقة البرلس بمحافظه كفر الثيخ.

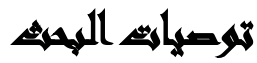

\section{أولاً: توصيات قصيرة الأجل:}

1-التحول من تصدير المعادن الخام إلى تصنيعها وإمداد الأسواق المحلية باحتياجاتها من المعادن عن طريق الفصل وإضافه قيمة مضافة.

r-التشغيل والاستفادة من الاحتياطي التتجيمي، وكذلك البحث عن أماكن جديدة للتنقيب

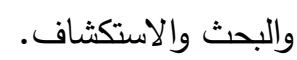

r- العمل على الحفاظ على الكوادر البشرية، وإثقال الخبرات بالدراسات العلمية وتوفير الدورات للاطلاع على التجارب الدولية للمشروعات المماثلة لفصل ومعالجة الرمال السوداء. ثانيًا: توصيات طويلة الأجل: ا-العمل على تحسين الوضع البيئي والسيطرة على الأضرار البيئية الناتجة عن عمليات فصل المونازيت بالاستعانة بالمعدات الحديثة والمتطورة. r-التمسك بتتفيذ استراتيجة التتمية المستدامة، وتتفيذ إجراءات حماية الموارد المعدنية والمعالجة الآمنة للمونازيت والعمل بتوازن بين التتمية الاقتصادية وحماية البيئة.

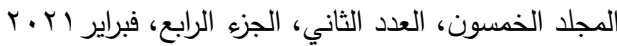

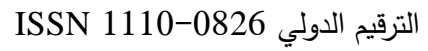


r- الاهتمام بمجال البحث والتطوير والابتكار والمفاضلة بين مواقع استغلال الرمال السوداء

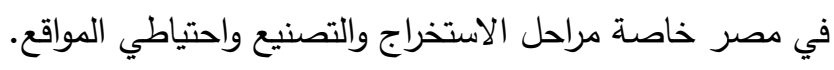

\section{المرالمئ}

ابراهيم السيد زكريا: مدخل مُقترَح لاستخدام الضرائب في مكافحة التلوث البيئي في جمهورية مصر العربية دراسة ميدانية مجلة البحوث المالية والتجارية العددء كلية التئية التجارة

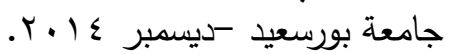

حمدي سيف النصر : الملخص التنفيذي لدراسة الجدوي الثاملة لاستغلال الرمال السوداء

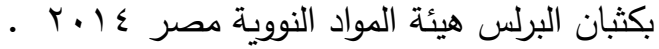

حمدي سيف النصر، كمال عبد الباقي: تقرير تقني مختصر عن التخطيط لمعالجة معدن

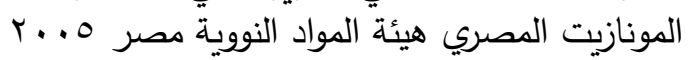

سحر أحمد حسن: الأهمية النسبية لقطاع التعدين في الاقتصاد القومي المصري - دراسية

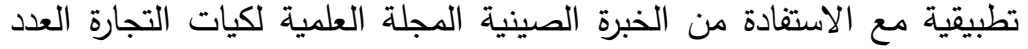

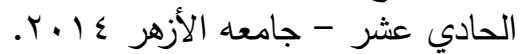

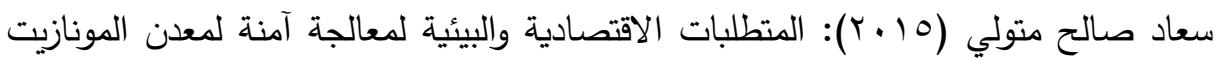
المصري رسالة دكتوراه معهد الدراسات والبحوث البيئية، جامعة عين شمس.

محمد عز الدين حلمي (عـ91 ()): كتاب علم المعادن. مكتبة أنجلو المصرية.

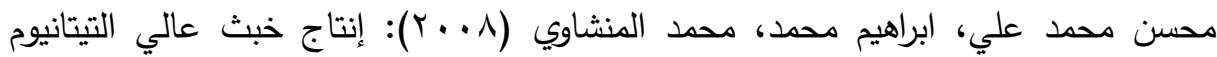
المتواجدة في الرمال السوداء - الامنيت هيئة المواد النووية.

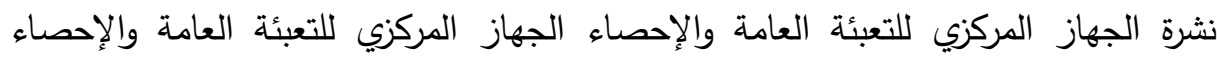

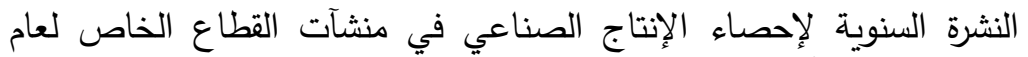

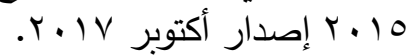

Abdullah Muhammad Attiah (2013): Environmental Assessment of Rosetta Area Mediterranean Sea Coast Egypt- MPA Faculty of Science Zagazig University.

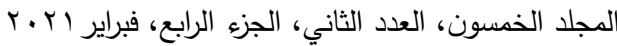

$$
\begin{aligned}
& \text { الترقيم الدولي 0826-0 التيوني }
\end{aligned}
$$




$$
\begin{aligned}
& \text { مجلة العلوم البيئية } \\
& \text { معهد الدراسات والبحوث البيئية - جامعة عين شمس آلئس } \\
& \text { جهاد سعيد السيد وآخرون }
\end{aligned}
$$

Ayman A. Halawa and Kandil M. Kandil: Specification of the Egyptian Garnet Concentrate for the industrial uses Compared With Some World Products Sedimentology of Egypt vol 172009

Aziza Ibrahim Lutfi: Recovery of Uranium During Treatments of Low Grade Egyptian Monazite Sand Sulfuric Acid- Faculty of Science- Ain Shams University

K. ARABIE N. M ABD EL MONEMB El MonemI.M ISMAILB OS HEIAIY AND E. SALAMAA: On the Recovery Of Rare Earth Elements From Low Grade Egypition Monzite BY Sulphuric Acid Process Nuclear Materials Authority Faculty of Science -El Azhar University Joun2006

Mohamed I. Moustafa and Nasr A. Abdel Fattah: Physical Beneficiation and Chemical Processing Of The Egyptian Beach Monazite Sedimentology of Egypt Vol 17-2009

Yassin A. Abdel Razek; Antar F. Bakhit and Ahmed F. El-Hadary: Terrestrial Radlation and Estimation of Its Hazards At Baltim Area Sedimentology of Egypt vol 172009

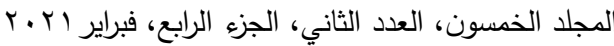

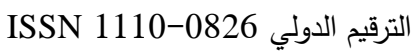




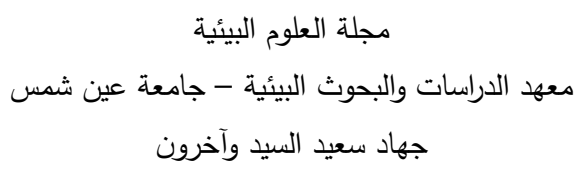

\title{
AN ECONOMIC AND ENVIRONMENTAL STUDY \\ ON THE ADDED VALUE OF THE SEPARATION, TREATMENT AND PROCESSING OF MONAZITE \\ FROM EGYPTION BLACK SAND \\ AN APPLIED STUDY \\ ON NUCLEAR MATERIAL AUTHORITY
}

\author{
Gehad S. Barakat ${ }^{(1)}$; Abeer F. Ali ${ }^{(2)}$ and Hamed I. Mirah ${ }^{(3)}$ \\ 1) Post graduate student at Institute of Environmental Studies \& \\ Research, Ain Shams University 2) Faculty of Commerce, Ain Shams \\ University 3)Nuclear Material Authority
}

\begin{abstract}
The black sand is treasure from the Egyptian treasure. The black sand distributed along the Mediterranean sea from Abu Qir in the west to Rafah in the east, and wadi Duaait on the Red sea at the southern eastern desert the concentration of heavy minerals is increased by the transgression and regression wave current on the coastal plain the black sand show a lenses along the beach. The mining and separation of black sand is consider very important train of development and economic for commercial and strategic position. The black sand contain ilmenite, magnetite, rutile, zircon, garnet, and monazite. These minerals separated by physics (electrostatic) properties of these minerals The exploitation of separation and treatment processing contribute to rising (goodness) the commercial balance, and increase exports and domiciliation the big industries and arrangement flow of increasing the

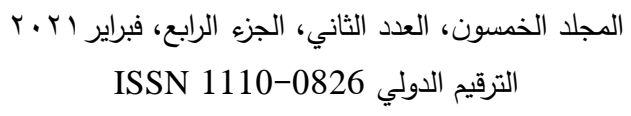




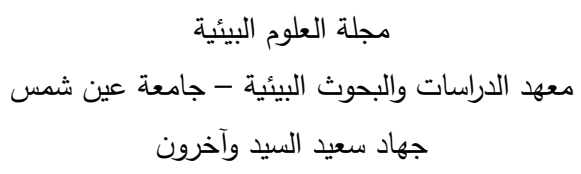

foreign criticism and fined the new job chances, rich all or part of importation maters and minerals, so this give goodness the production balance and commutation international roles (laws), and activation the commercial, also treatment the wrongs of commercial and social skeleton This industry effect on the industrial division and put the coasts of different concentrate and separated factories with agree to the Egyptian site for mining where has recover row which indicated by geological studies and the price of machines.So must defined the roles between Nuclear materials authority (NMA) and mineral technology company. So the NMA responsible for the studies, prospecting and exploration data. The environmental side for this project must finishing the rubbish by safe roles according to the cycle system according to the central government.

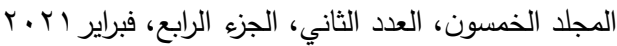

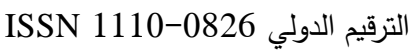

